\title{
The Association of Attitude, Perceived Behavioral Control, and Intention with Fruit and Vegetable Intake among Rural West Virginian Residents with Pre-diabetes in Mineral and Hampshire Counties
}

Diana Leigh Niland

West Virginia University, diana.niland@mail.wvu.edu

Follow this and additional works at: https://researchrepository.wvu.edu/etd

Part of the Public Health and Community Nursing Commons

\section{Recommended Citation}

Niland, Diana Leigh, "The Association of Attitude, Perceived Behavioral Control, and Intention with Fruit and Vegetable Intake among Rural West Virginian Residents with Pre-diabetes in Mineral and Hampshire Counties" (2019). Graduate Theses, Dissertations, and Problem Reports. 4056.

https://researchrepository.wvu.edu/etd/4056

This Dissertation is protected by copyright and/or related rights. It has been brought to you by the The Research Repository @ WVU with permission from the rights-holder(s). You are free to use this Dissertation in any way that is permitted by the copyright and related rights legislation that applies to your use. For other uses you must obtain permission from the rights-holder(s) directly, unless additional rights are indicated by a Creative Commons license in the record and/ or on the work itself. This Dissertation has been accepted for inclusion in WVU Graduate Theses, Dissertations, and Problem Reports collection by an authorized administrator of The Research Repository @ WVU.

For more information, please contact researchrepository@mail.wvu.edu. 
The Association of Attitude, Perceived Behavioral Control, and Intention with Fruit and Vegetable Intake among Rural West Virginian Residents with Pre-diabetes in Mineral and Hampshire Counties

\title{
Diana Niland
}

Dissertation submitted

to the School of Nursing at West Virginia University

in partial fulfillment of the requirements for the degree of

Doctor of Philosophy in

Nursing

\author{
Tara Hulsey, PhD, RN, CNE, FAAN, Chair \\ Mary Jane Smith, PhD, RN, FAAN \\ Suzy Walter, PhD, FNP-BC, CNRN \\ Usha Sambamoorthi, PhD \\ School of Nursing \\ Morgantown, WV
}

Keywords: theory of planned behavior, fruit and vegetable intake, prediabetes 


\begin{abstract}
The Association of Attitude, Perceived Behavioral Control, and Intention with Fruit and Vegetable Intake among Rural West Virginian Residents in Mineral and Hampshire Counties with Pre-diabetes

Diana Niland

Introduction: Pre-diabetes affects approximately 84.1 million adults in the United States. Prediabetes is one of the leading predictors of type 2 diabetes. West Virginia ranks number one in the prevalence of diabetes. Fruit and vegetable intake may assist in reducing risk for prediabetes. However, most adults do not consume the recommended daily amount. There are no studies investigating the fruit and vegetable intake (FVI) of rural West Virginian residents with pre-diabetes.
\end{abstract}

Method: After IRB approval and informed consent, 74 participants from two counties in West Virginia were recruited over three weeks for the study. Data were collected using a demographic survey, a Theory of Planned Behavior (TPB) Questionnaire, the Behavioral Risk Factor Surveillance Survey (BRFSS) Fruit and Vegetable Module, and the CDC Pre-diabetes Screening Risk Test. Data were analyzed using SPSS 25, with alpha set at .05. Sample frequencies and descriptives were analyzed. Statistical analyses to answer the research questions included $t$-tests and multiple linear regressions.

Results: Participants were mainly white (94\%), middle aged $(M=48.8, \mathrm{SD}=17.5)$, married (55.4\%), women $(63.5 \%)$ with college/technical education $(56.8 \%)$ and household income greater than $\$ 40,000$ (55.4\%). Participants with less than college/technical education had significantly lower FVI $(p=0.004)$. Two TPB variables - perceived behavioral control (PBC) and intention - were highly correlated $(\mathrm{r}=0.45, p=0.001)$. Attitude was not associated with FVI. After adjusting for education, the regression model explained $11.8 \%$ of FVI associated with attitude, $15.9 \%$ of FVI associated with PBC, and $18.2 \%$ of FVI associated with intention.

Conclusion: Higher PBC and intention toward FVI were associated with increased FVI. Increased FVI may play a role in preventing diabetes as well as other chronic conditions. Interventions to increase FVI in individuals with pre-diabetes aimed at targeting an individual's PBC and intention may assist in stopping or delaying the progression of pre-diabetes to diabetes. Consideration should also be given to the individual's educational level and the impact it may have on fruit and vegetable intention and actual intake. 


\section{List of Tables}

Table $1 \quad$ Fruit and Vegetable Intake Study Protocol

Table 2 Variables in the Association of Attitude, Perceived Behavioral Control, and Intention with Fruit and Vegetable Intake among Rural West Virginian Residents with Pre-diabetes Study

Table 3 Description of Demographic Characteristics of the Sample Adults with Pre-Diabetes in West Virginia

Table 4 Description of Perceived Behavioral Control, Attitude, and Demographic Characteristics of Adults with Pre-Diabetes in West Virginia

Table 5 Description of Usual Fruit and Vegetable Intake by Demographic Characteristics in Adults with Pre-Diabetes in West Virginia

Table 6 Adjusted Associations of Attitude, Perceived Behavioral Control, Intention, and Usual Fruit and Vegetable Intake Controlling for Education from Separate Multiple Linear Regressions on Usual Fruit and Vegetable Intake for Adults with Pre-Diabetes in West Virginia

Table 7 Adjusted Associations of Attitude, Perceived Behavioral Control, and Education Usual Fruit and Vegetable Intake from Multiple Linear Regression for Adults with Pre-Diabetes in West Virginia

Table 8 Adjusted Associations of Attitude, Intention and Education to Usual Fruit and Vegetable Intake from Multiple Linear Regression for Adults with Pre-Diabetes in West Virginia 


\section{List of Figures}

Figure $1 \quad$ Literature search process

Figure 2 Associations of fruit and vegetable intake to promote fruit and vegetable intake using the theory of planned behavior as the guiding framework

Figure 3 Associations of attitude to usual fruit and vegetable intake in West Virginian residents with pre-diabetes in Mineral and Hampshire counties.

Figure 4 Associations of perceived behavioral control to usual fruit and vegetable intake in West Virginian residents with pre-diabetes in Mineral and Hampshire counties.

Figure 5 Associations of intention to usual fruit and vegetable intake in West Virginian residents with pre-diabetes in Mineral and Hampshire counties. 


\section{List of Appendices}

Appendix A Demographics Survey and Instruments

Appendix B Pilot Study Questions

Appendix C CDC Prediabetes Screening Test 


\section{List of Abbreviations}

$\begin{array}{ll}\text { ADA } & \text { American Diabetic Associations } \\ \text { BMI } & \text { Body Mass Index } \\ \text { BRFSS } & \text { Behavior Risk Factor Surveillance System } \\ \text { CDC } & \text { Center for Disease Control and Prevention } \\ \text { CDE } & \text { Certified Diabetes Educator } \\ \text { FVI } & \text { Fruit and Vegetable Intake } \\ \text { HIPAA } & \text { Health Information Portability and Accountability Act } \\ \text { IRB } & \text { Institutional Review Board } \\ \text { MMWR } & \text { Morbidity and Mortality Weekly Report } \\ \text { PBC } & \text { Perceived Behavioral Control } \\ \text { PCP } & \text { Primary Care Provider } \\ \text { SD } & \text { Standard Deviation } \\ \text { SE } & \text { Standard Error } \\ \text { TPB } & \text { Theory of Planned Behavior } \\ \text { VIF } & \text { Variance Inflation Factor } \\ \text { WVU } & \text { West Virginia University } \\ & \end{array}$




\section{Table of Contents}

List of Abbreviations

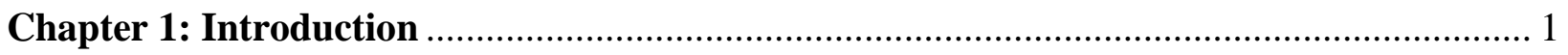

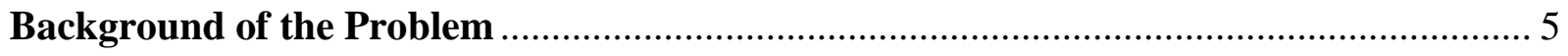

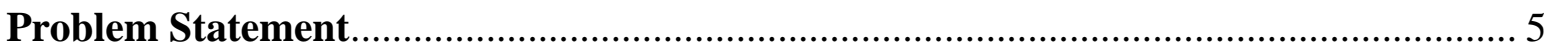

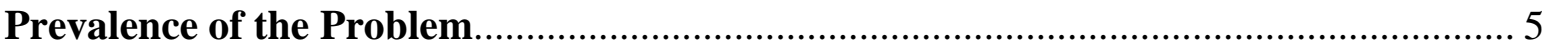

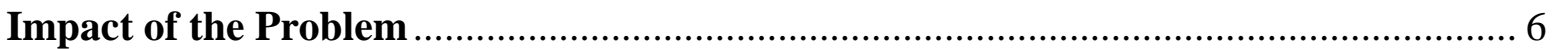

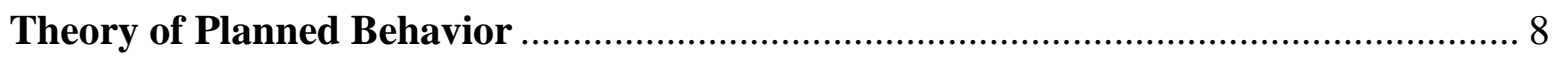

Major Constituents of the Study ............................................................................. 13

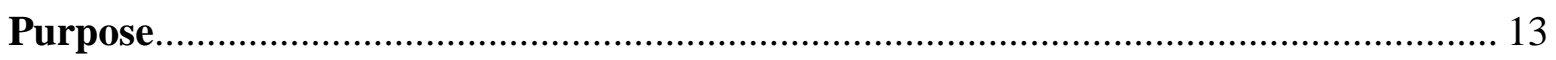

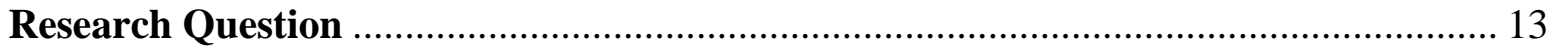

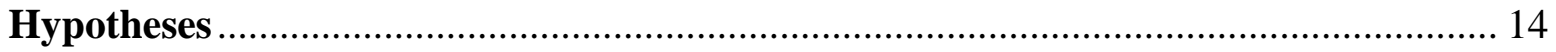

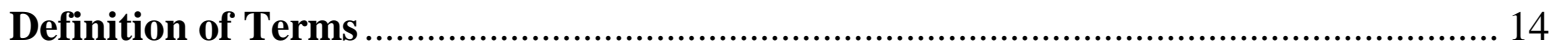

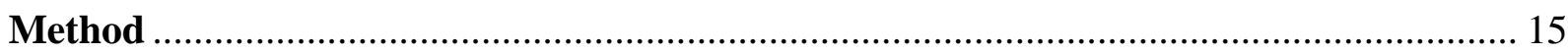

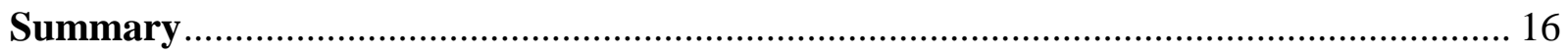

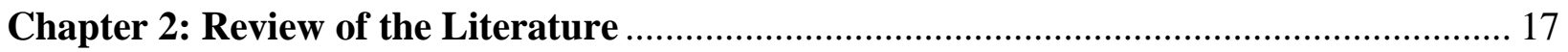

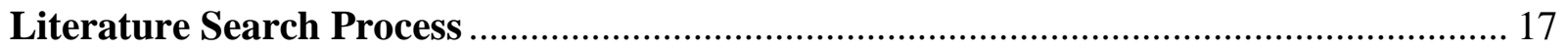

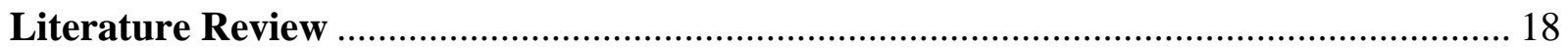

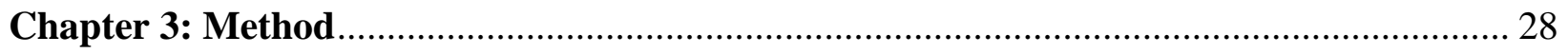

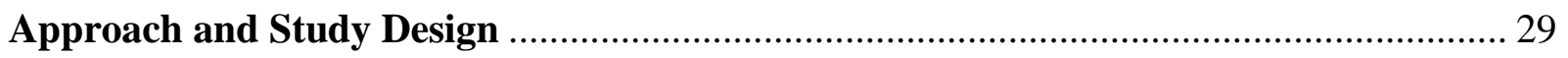

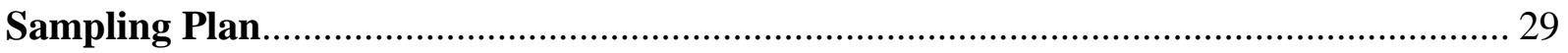

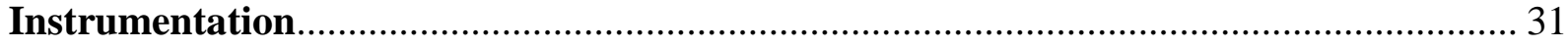

Conceptual and Operational Definitions of Variables ................................................ 33

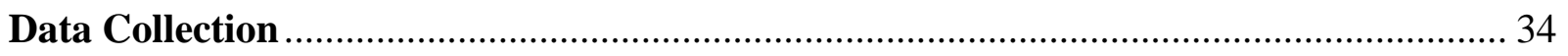

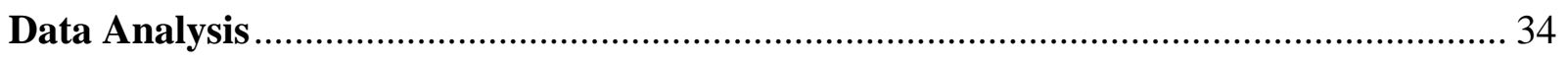

Human Rights and Ethical Considerations ......................................................... 35

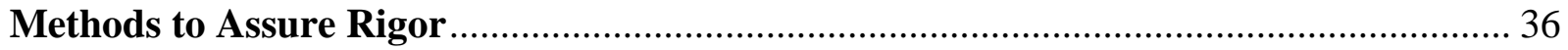

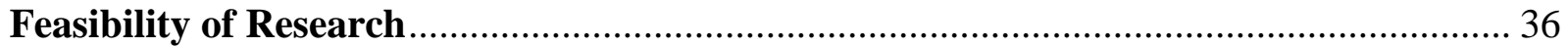

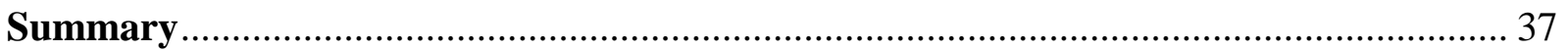

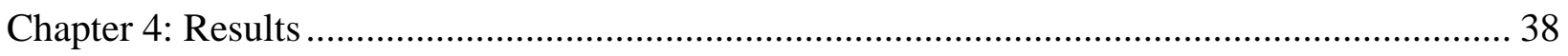

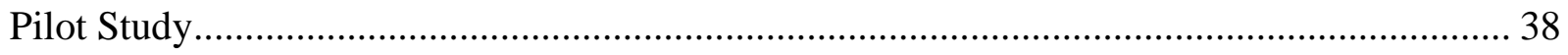

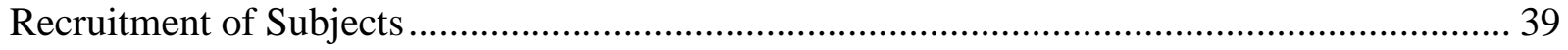

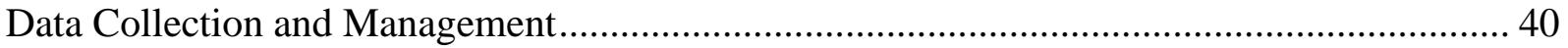




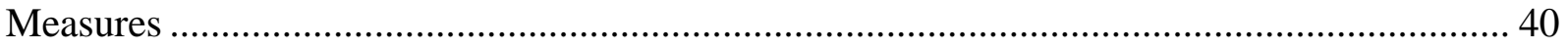

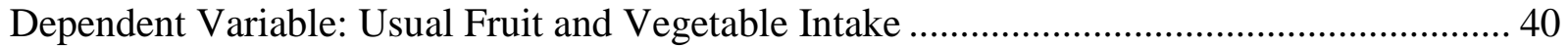

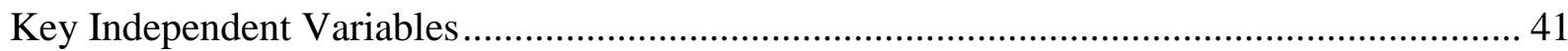

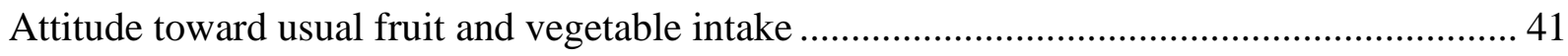

Perceived behavioral control to usual fruit and vegetable intake ............................................. 41

Intention toward usual fruit and vegetable intake .................................................................. 42

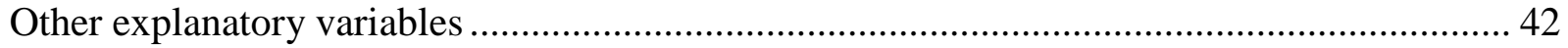

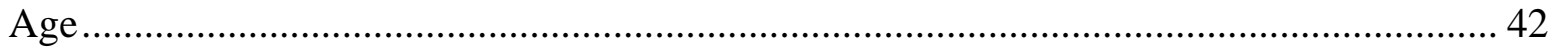

Sex

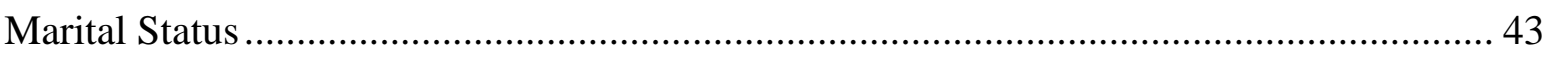

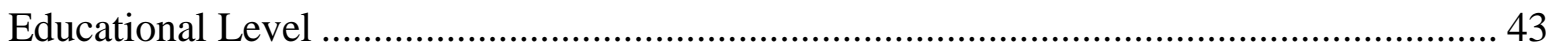

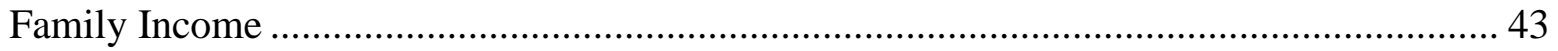

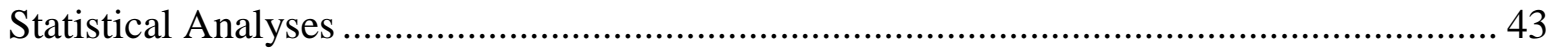

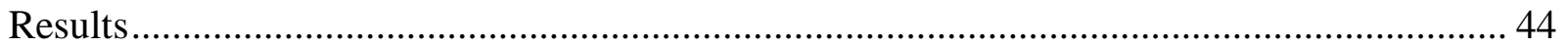

Description of the Sample by Demographic Characteristics ............................................... 44

Description of the Sample by risk factors for Diabetes ........................................................ 44

Attitude toward Fruit and Vegetable Intake by demographic characteristics........................ 44

Perceived behavioral control toward Fruit and Vegetable by demographic characteristics . 45

Intention to take Fruit and Vegetable Intake by demographic characteristics ....................... 45

Association of Demographic Characteristics to Fruit and Vegetable intake ........................ 45

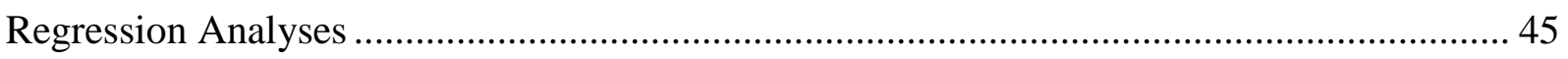

Unadjusted Association of Attitude to Usual Fruit and Vegetable Intake............................. 46

Unadjusted Association of Perceived Behavioral Control to Usual fruit and vegetable intake 46

Unadjusted Association of Intention to Usual Fruit and Vegetable intake.......................... 46 Adjusted Associations of Attitude, Perceived Behavioral Control and Intention to Usual fruit and vegetable intake: Multiple Linear Regressions .................................................................. 47

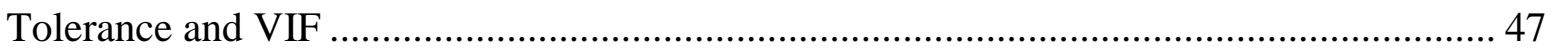

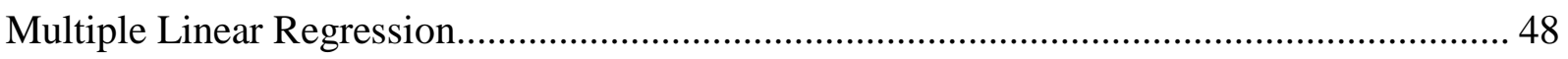

Multiple Linear Regression of Usual Fruit and Vegetable Intake: Adjusted for education .... 48

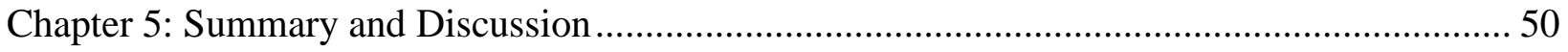

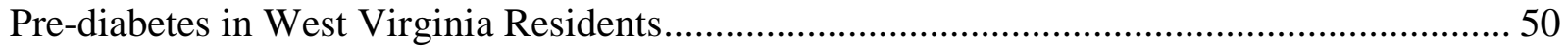

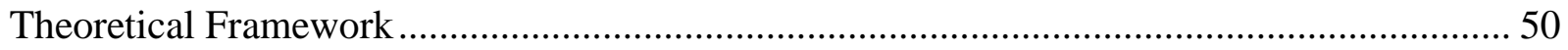


Summary of Findings: Fruit and Vegetable Intake among West Virginia Residents............. 51

Comparison of Study Findings to Prior Studies on Fruit and Vegetable Intake..................... 51

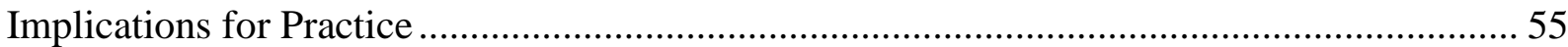

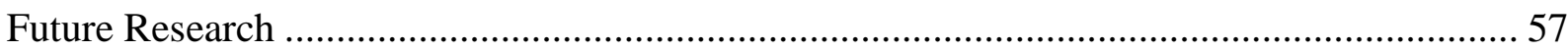

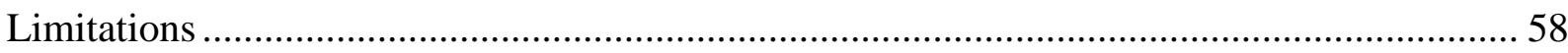

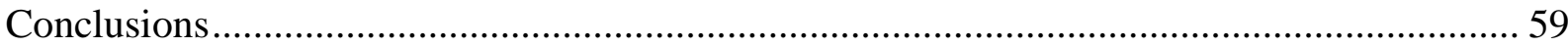

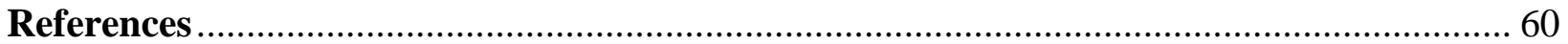

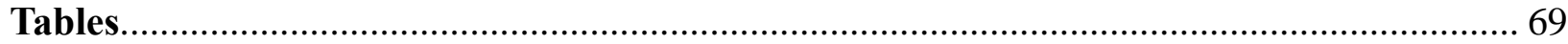

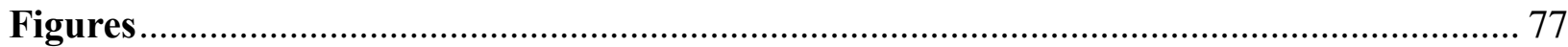




\section{Chapter 1: Introduction}

Pre-diabetes is one of the leading predictors of type 2 diabetes. As part of the Appalachian states, West Virginia ranks number one in the prevalence of diabetes. Similarly, other Appalachian states have high rates of diabetes (Ohio ranks $19^{\text {th }}$; Maryland ranks $21^{\text {st }}$; Pennsylvania ranks $15^{\text {th }}$; Kentucky ranks $5^{\text {th }}$, and Virginia ranks $27^{\text {th }}$ ), but not to the extent of West Virginia (The State of Obesity, 2018). The American Diabetes Association (ADA) (2018) estimates 84.1 million adults have pre-diabetes. Pre-diabetes is when an individual's blood glucose level is higher than normal but not high enough to be diagnosed with diabetes (CDC, 2017). Risk factors for pre-diabetes include being overweight, 45 years or older, having a sibling or parent with diabetes, physical inactivity and having gestational diabetes (CDC, 2017). Interventions that effectively address the risk factors associated with pre-diabetes are important for early management and to avoid progression of this chronic illness. Along with weight loss and physical activity, fruit and vegetable intake is an important component in diabetes prevention. However, the vast majority of adults are not consuming the recommended daily amount of fruits and vegetables (Centers for Disease Control and Prevention, 2015), despite evidence supporting the reduction in risk for pre-diabetes associated with fruit and vegetable intake (Cooper et al., 2015; Kurotani et al., 2013; Safabakhsh et al., 2017). The Division of Health Promotion and Chronic Disease (2018) reports that 91.7\% of West Virginians' daily intake of fruit and vegetables is less than the recommended amount of five servings per day.

There are no studies that focus on associations of fruit and vegetable intake in rural residents with pre-diabetes, making it difficult to target fruit and vegetable intake. Further, studies addressing factors associated with fruit and vegetable intake in adults with pre-diabetes are needed to develop intervention targeted specifically at this behavior. This study will 
investigate the association of theory of planned behavior concepts known to be predictors of fruit and vegetable intake among college students (Evans, Kawabata, \& Thomas, 2015; Godinho, Alvarez, Lima, \& Schwarzer, 2014; Kothe \& Mullan, 2015; Tomasone, Meikle, \& Bray, 2015) with fruit and vegetable intake among West Virginian residents with pre-diabetes in a rural area. Although diabetes prevention efforts address fruit and vegetable intake, there is no specific focus on how to improve fruit and vegetable intake in a rural population. Increasing fruit and vegetable intake offers an added benefit in preventing diabetes (Cooper et al, 2015; Kanaya et al, 2012; Kurotani et al., 2013; Safabakhsh, 2017). Even though physical activity is important, weight loss is associated with improved eating habits (Centers for Disease Control and Prevention, 2015a). Though fruit and vegetable intake has not been directly associated with weight loss, fruit and vegetable intake has been associated with weight management (Centers for Disease Control and Prevention, 2015a; Rolls, Ello-Martin, \& Tohill, 2004; The World Health Organization, 2018). Thus, developing intervention with a focus on fruit and vegetable intake will most likely assist in weight management and disease prevention. Studies have shown that physical activity alone does not lead to weight loss (Luke \& Cooper, 2013; Pontzer et al., 2016). With weight loss and physical activity as indicators of diabetes prevention, efforts are focused on these areas, but again few studies show what we do to increase the consumption of fruits and vegetables (Centers for Disease Control and Prevention, 2015c).

In the United States there are 30.1 million adults with diabetes (American Diabetes Association, 2018). West Virginia has the highest rate of type 2 diabetes (Trust for America's Health and Robert Wood Johnson Foundation, 2018). Type 2 diabetes is a disease that, if left uncontrolled, negatively affects an individual's health, including the cardiovascular system, nervous system, kidneys, and vision (American Diabetes Association, 2018). The Centers for 
Disease Control and Prevention (2017) state that pre-diabetes is a condition in which an individual's blood glucose level is higher than normal but not high enough to be diagnosed with diabetes. Therefore, determining factors for successful fruit and vegetable intake should be understood. Although studies have looked at associations of successful fruit and vegetable intake, most studies were conducted in the college health population and only one study looked at an adult rural population (Condrasky, Baruth, Wilcox, \& Carter, 2013).

Adding fruit and vegetable intake offers a bigger impact on weight loss than physical activity alone (Centers for Disease Control and Prevention, 2015a). The Centers for Disease Control and Prevention (2015b) recommend substituting high calorie foods with fruits and vegetables. The replacement of foods high in calories but low in nutrients with fruits and vegetables may assist with weight loss and the prevention of chronic disease (Centers for Disease Control and Prevention, 2015a). The World Health Organization (2018) reports that a diet rich in fruits and vegetables prevents weight gain, reduces the risk of preventable non-communicable disease, and prevents deaths attributable to inadequate intake of fruits and vegetables. Fruit and vegetable consumption may help to reduce adiposity, slow the progression of weight gain, and prevent weight gain when consumed along with physical activity and/or other dietary changes (Ledoux, Hingle, \& Baranowski, 2011). Diabetes prevention programs focus on monitoring calories and fat grams and less on the importance of fruit and vegetable consumption. Group Lifestyle Balance is a diabetes prevention program that suggests participants use the MyPlate example from the United States Department of Agriculture in which half of an individual's plate should be filled with fruits and vegetables (Diabetes Prevention Research Group, 2002). However, little emphasis is placed on identifying factors which contribute to healthy intake of fruit and vegetables in diabetes prevention efforts. 
Rural populations are at increased risk for poor fruit and vegetable intake due to several factors associated with poverty and rurality, including high cost of fresh produce, limited access to fruit and vegetables, and availability of unhealthy alternatives such as energy-dense foods (Dean \& Sharkey, 2011; Kamphuis et al., 2006). Individuals living in a rural area are often subject to spatial disparities including the distribution of food resources. Menezes, Costa, Oliveira, and Lopes (2017) found that low fruit and vegetable intake was associated with communities in which there is limited access to food sources including inadequate quality and variety of healthy food choices. Poverty also affects fruit and vegetable intake in rural communities. Adults with low income levels or living in poverty were found to have lower fruit and vegetable intake. This may be associated with the proportion of income available to be spent on fruits and vegetables (Storey \& Anderson, 2014). Middaugh, Fisk, Brunt, and Rhee (2012) found income directly influences the intake of fruit and vegetables when income reaches equal to or greater than $400 \%$ of the poverty threshold. However, it was also found that education mediated the difference between income levels, suggesting that education may aid in increasing an individual's fruit and vegetable intake (Middaugh et al., 2012).

The aims of this study are to (1) examine associations of attitude, perceived behavioral control and intention of fruit and vegetable intake to usual fruit and vegetable intake in Mineral and Hampshire county residents in rural West Virginia with pre-diabetes.and (2) determine the amount of variance contributed by each variable in the association with usual intake of fruits and vegetables among West Virginian residents in Mineral and Hampshire County residents with pre-diabetes. 


\section{Background of the Problem}

\section{Problem Statement}

Diabetes is one of the most common reasons for adult primary care visits (National Center for Healthcare Statistics, 2017). Poor monitoring for pre-diabetes and lack of intervention lead to the progression of type 2 diabetes (Centers for Disease Control and Prevention, 2015a). Diabetes affects quality of life related to complications associated with the disease, such as blindness, retinopathy, and end stage renal disease, and comprehensive diabetes treatment (Huang, Brown, Ewigman, Foley, \& Meltzer, 2007). Successful management for prediabetes includes weight loss and physical activity but is most closely associated with adequate fruit and vegetable intake. This study will look at associations between attitude, perceived behavioral control, and intention, and fruit and vegetable intake.

Adults living in rural West Virginia have high rates of pre-diabetes. Pre-diabetes left untreated may progress to the chronic disease of diabetes. There have been no studies in rural West Virginian residents with pre-diabetes that specifically examine the relationship between fruit and vegetable intake and a person's attitude, perceived behavioral control, and intention. The problem this investigation will address is examining the association of fruit and vegetable intake with persons diagnosed with prediabetes in rural Appalachia.

\section{Prevalence of the Problem}

The ADA (2018) reports that approximately 30.3 million adults have diabetes and 84.1 million adults have pre-diabetes in the United States. The West Virginia Department of Health and Human Resources and the Bureau for Public Health (n.d.) report that more than one in eight West Virginian adults have diabetes and one in 12 West Virginian adults have pre-diabetes. The Trust for Americas Health and Robert Wood Johnson Foundation reports that West Virginia is 
ranked number one as the highest rate of type 2 diabetes in the nation. The Centers for Disease Control and Prevention (2016) report that, without intervention, 15-30\% of adults with prediabetes will develop type 2 diabetes within five years; the University of Pittsburgh (2018) reports that $50 \%$ of adults with pre-diabetes are likely to develop diabetes within 10 years.

The two main goals of diabetes prevention programs are to increase participants' physical activity to 150 minutes per week and reduce participant's beginning weight by five to seven percent. Fruit and vegetable intake is associated with weight loss (Centers for Disease Control and Prevention, 2015a). However, most adults do not meet the recommended daily fruit and vegetable intake. The Centers for Disease Control and Prevention (2015c) Morbidity and Mortality Weekly Report (MMWR) revealed that only $7.7 \%$ of West Virginian adult respondents to the Behavioral Risk Factor Surveillance System (BRFSS) met the federal recommendations for daily fruit intake and only $6.6 \%$ met the recommendations for daily vegetable intake. The National Center for Chronic Disease Prevention and Health Promotion's (2013) State Indicator Report on fruit and vegetable intake shows that the median daily fruit and vegetable intake for West Virginian adults is 1.0 serving for fruits and 1.5 servings for vegetables per day.

\section{Impact of the Problem}

Pre-diabetes is a disease that affects millions of adults in the United States. Without intervention, individuals with pre-diabetes are 15 to $30 \%$ more likely to develop diabetes within

five years (National Center for Chronic Disease Prevention and Health Promotion, n.d.) and 50\% within 10 years (University of Pittsburgh, 2018); in addition, they are more likely to subsequently develop complications such as cardiovascular disease, amputation, and kidney disease that may result in death. West Virginian residents with pre-diabetes, who are not consuming the recommended daily intake of fruits and vegetables are at increased risk for 
developing diabetes and subsequent complications. Knowledge gained from this study may improve understanding of factors associated with fruit and vegetable intake.

The progression of this disease also has associated economic costs. It is estimated that the financial burden of pre-diabetes and diabetes equates to approximately $\$ 2.5$ billion each year for West Virginia (American Diabetes Association, n.d). The economic cost of pre-diabetes in West Virginia is approximately \$267 million (Dall et al., 2014). Prediabetes left untreated can progress to diabetes. West Virginia has the highest rate of diagnosed diabetes in the United States (Dall et al., 2014), resulting in increased financial burden. In 2012, the total direct costs associated with diagnosed diabetes, undiagnosed diabetes, prediabetes and gestational diabetes was estimated to be $\$ 1.9$ billion in West Virginia (American Diabetes Association, n.d.). The indirect costs from lost productivity due to diabetes was estimated at $\$ 627$ million in West Virginia (American Diabetes Association, n.d.).

The financial burden attributable to pre-diabetes is partially due to diabetes prevention efforts. In 2016, the Centers for Disease Control and Prevention spent \$430,866 on diabetes prevention and education in West Virginia (American Diabetes Association, n.d.). Pre-diabetes continues to be a concern for West Virginia residents, though participation in diabetes prevention programs may reduce participant's risk of developing diabetes by 58 percent (Diabetes Prevention Research Group, 2002). Many West Virginian residents are unaware they have prediabetes. The West Virginia Behavioral Risk Factor Surveillance System Report (2012) states that approximately $8.3 \%$ of adults in WV have pre-diabetes. The American Diabetes Association's (n.d.) report The Burden of Diabetes in West Virginia indicates that 518,000 West Virginian adults are living with prediabetes. Yet only $6.7 \%$ of West Virginian adults report they have ever been told they have pre-diabetes (Centers for Disease Control and Prevention, 2016). 
Without intervention, individuals with pre-diabetes are 15 to 30 percent more likely to develop diabetes within five years (National Center for Chronic Disease Prevention and Health Promotion, n.d.) and subsequently develop complications such as cardiovascular disease, amputation, and kidney disease that may result in death.

\section{Theory of Planned Behavior}

Icek Ajzen's theory of planned behavior $(1991,2005)$ will provide the theoretical underpinnings for this study. The theory of planned behavior is an extension of Ajzen's theory of reasoned action (Ajzen, 1991). Ajzen originally developed the theory of planned behavior to predict planned behavior including those behaviors under volitional control. The theory of planned behavior is a social cognitive theory that assumes an individual's intention to perform a behavior is predicted by the individual's attitude, subjective norm, and perceived behavioral control (Ajzen, 2011). Ajzen added the perceived behavioral control concept to address behaviors that may not be under volitional control. The theory asserts the most important determining factor of whether a behavior is carried out is the intention to perform the behavior. The theory also postulates: an individual's behavior is under voluntary control of the individual; the individual has the ability to contemplate the consequences of his or her action and decide whether to engage in a specific behavior; and an individual's intention to perform the specific behavior should correspond to whether the individual performs the behavior (Ajzen, 1991).

The focus of the theory of planned behavior is that achievement of a certain behavior is dependent upon the individual's intention and perceived behavioral control. There are concepts that represent an individual's control over their behavior; this includes attitude and perceived behavioral control. A main concept of the theory is intention. Intention is determined by the individual's attitude, subjective norm, and perceived behavioral control. The theory of planned 
behavior model is used to determine how likely an individual is to engage in a certain behavior. In order to predict an individual's behavior, concepts of the theory of planned behavior are considered. Behavior is guided by three salient beliefs: behavioral beliefs which affect attitude toward the behavior, normative beliefs which result in social pressure (subjective norm), and control beliefs which yield perceived behavioral control.

Attitude. The concept of attitude toward behavior represents the individual's positive or negative feelings toward performing the behavior. Attitude develops from the salient beliefs about the object of the attitude (Ajzen, 2005). Each belief is linked to either a positive or negative association with the behavior. If an individual holds a positive belief toward a behavior, then the individual will have a more favorable attitude toward the behavior and be more likely to participate in the behavior. However, if an individual holds a negative belief toward a behavior, the individual believes participating in the behavior will result in negative outcome, and the individual will be less likely to participate in the behavior (Ajzen, 2005).

Subjective norm. The concept of subjective norm is the perceived social pressure to engage or not engage in behavior (Ajzen, 2005). Subjective norm is determined by the normative beliefs (perceived behavioral expectations of important social referents) concerning the expectations of the referents. Each normative belief is weighted by motivation to comply with the referent in question (Ajzen, 1991). An individual who believes important referents think the individual should perform the behavior will feel pressure to carry out the behavior. Likewise, the individual who perceives that important referents disapprove of a behavior will feel social pressure to not engage in the behavior.

Perceived behavioral control. Perceived behavioral control refers to an individual's ability to perform a behavior and represents the individual's perception of whether the behavior 
will be easy or difficult (Ajzen, 1991). Perceived behavioral control is determined by control beliefs (perceived presence of factors that facilitate or hinder performance of behavior).

Perceived behavioral control increases when the individual perceives they have more confidence and there are more resources. Perceived behavioral control, along with intention, can be used to make predictions about behavior (Ajzen, 2005).

Intention. Intention is described as an individual's conscious decision (motivation) to perform a specific behavior (Ajzen, 2005). Intention is the immediate antecedent of behavior based on an individual's attitude, subjective norm, and perceived behavioral control. Each predictor is weighted for its importance in relation to the behavior (Ajzen, 2005). The more the individual is motivated to engage in a behavior, the more likely he/she will be to perform the behavior. The theory of planned behavior can be used to guide inquiry into diabetes prevention. Ajzen's theory of planned behavior, as applied to adults with pre-diabetes, is appropriate because understanding the relationships between attitude toward fruit and vegetable intake, perceived behavioral control of fruit and vegetable intake and intention to consume fruit and vegetables will act as a direct antecedent of fruit and vegetable intake behavior. In previous studies, subjective norm has not been associated as a predictor of fruit and vegetable intake (Emanuel, McCully, Gallagher, \& Updegraff, 2012; Kothe \& Mullan, 2015; Lien, Lytle, \& Komro, 2016; Tomasone et al., 2015). Therefore, subjective norm will not be included in the proposed study. To increase the behavior of fruit and vegetable intake in adults with pre-diabetes, nurses should know what factors affect the individual's likelihood to consume fruit and vegetables. The application of the theory of planned behavior may allow for the nurse to recognize attitudes, perceived behavioral control, and intentions toward fruit and vegetable intake and personalize interventions to better assist the individual to meet diabetes prevention program goals. 


\section{Significance of the Study}

This study will (1) examine the relationship between three associations (attitude, perceived behavioral control, and intention) of fruit and vegetable intake and actual fruit and vegetable intake in rural West Virginian residents of Mineral and Hampshire counties with prediabetes and (2) determine the amount of variance contributed by each variable in the association with usual intake of fruits and vegetables among West Virginian residents in Mineral and Hampshire County residents with pre-diabetes. This study is expected to contribute to knowledge on health promotion, professional practice, and cost to society.

It is known that an increase in fruit and vegetable intake improves health. This study will contribute to the knowledge base on health promotion by providing information on associations of fruit and vegetable intake in rural West Virginian residents of Mineral and Hampshire counties with pre-diabetes. Results from this study may inform health promotion efforts, allowing for efforts to be directed toward the associated variable of fruit and vegetable intake that will have the most impact. Results from this study may offer diabetes prevention programs additional information in determining intention to consume fruit and vegetable intake of rural West Virginia residents of Mineral and Hampshire counties with pre-diabetes. The information of which association of fruit and vegetable intake will have the most impact on fruit and vegetable consumption will allow for health promotion efforts to be targeted toward the associated variable most likely to impact fruit and vegetable intake behavior. This knowledge can be incorporated into health promotion models aimed at fostering change in perceptions toward fruit and vegetable consumption and therefore impact behavior toward consuming fruit and vegetables. 
This study will examine associated variables having the largest effect on fruit and vegetable intake which may allow clinicians to focus on interventions targeted at increasing this behavior. Diabetes prevention programs evaluate diets in terms of calories and fat grams but they do not specifically address or monitor fruit and vegetable intake. Knowledge of associated variables affecting fruit and vegetable intake may provide diabetes prevention program coaches the ability to further target and address cognitive and behavioral actions to improve adherence to diabetes prevention goals. If a diabetes prevention coach is aware that a participant's attitude toward fruit and vegetable intake is the main reason they are not consuming the recommended amount, the coach may use techniques and interventions to target the participant's attitude toward fruits and vegetables. In diabetes prevention, correspondence between the participant and the program coach can be further tailored to address barriers to fruit and vegetable consumption through food journaling, which is already a component of diabetes prevention programs.

Determination of associations of fruit and vegetable intake may lead to more effective interventions; thus, reducing the economic burden of treatment for diabetes. Dall et al. (2014) report the economic burden associated with a diagnosis of diabetes in 2012 exceeded $\$ 300$ billion, contributed to excess medical costs, and reduced productivity. Knowledge of fruit and vegetable intake may help to reduce costs indirectly by allowing for more targeted and effective interventions. Knowledge of the relationship of associated variables for fruit and vegetable intake can be utilized to reduce costs by tailoring interventions to be most effective toward the described rural population.

Information from this study will serve as a foundation for future research. This study will be the first to examine associations of fruit and vegetable intake in rural West Virginian residents 
of Mineral and Hampshire counties with pre-diabetes and will offer a description of this population in relation to their attitude, perceived behavioral control, and intention to consume fruits and vegetables. Given the contribution to knowledge, health and well-being, practice implications, and cost, this study may make an impact in myriad areas.

\section{Major Constituents of the Study}

\section{Purpose}

The purpose of this study was to examine the relationships between fruit and vegetable attitude, perceived behavior control, intention, and usual intake among rural West Virginia residents of Mineral and Hampshire counties with pre-diabetes.

\section{Research Question}

The purpose of this study was addressed with the following four research questions:

a. How are fruit and vegetable attitude and fruit and vegetable perceived behavioral control associated with fruit and vegetable intention among rural West Virginia residents of Mineral and Hampshire counties with pre-diabetes?

b. What is the relationship between fruit and vegetable attitude and usual fruit and vegetable intake among rural West Virginia residents of Mineral and Hampshire counties with pre-diabetes?

c. What is the relationship between fruit and vegetable perceived behavior control and usual fruit and vegetable intake among rural West Virginia residents of Mineral and Hampshire counties with pre-diabetes?

d. What is the relationship between fruit and vegetable intention and usual fruit and vegetable intake among rural West Virginia resident of Mineral and Hampshire counties with pre-diabetes? 


\section{Hypotheses}

The hypotheses are stated as follows:

a. Fruit and vegetable attitude and fruit and vegetable perceived behavioral control will be significantly associated with fruit and vegetable intention to consume fruits and vegetables among rural West Virginia residents of Mineral and Hampshire counties with pre-diabetes.

b. There is a positive association between fruit and vegetable attitude and usual fruit and vegetable intake among rural West Virginia residents of Mineral and Hampshire counties with pre-diabetes.

c. There is a positive association between fruit and vegetable perceived behavior control and usual fruit and vegetable intake among rural West Virginia residents of Mineral and Hampshire counties with pre-diabetes.

d. There is a positive association between fruit and vegetable intention and usual fruit and vegetable intake among rural West Virginia residents of Mineral and Hampshire counties with pre-diabetes.

\section{Definition of Terms}

For the purpose of this study the following definitions of pre-diabetes, fruit and vegetable intake, attitude, perceived behavioral control, and intention were used.

- Prediabetes: A score of nine or higher on the Centers for Disease Control and Prevention's diabetes risk test, or having been diagnosed with gestational diabetes (Centers for Disease Control and Prevention, 2016). 
- Fruit intake: The consumption of "the usually edible reproductive body of a seed plant; especially one having a sweet pulp associated with the seed" (Oxford English Dictionary, 2018).

- Vegetable intake: The consumption of "a usually herbaceous plant (such as the cabbage, bean, or potato) grown for an edible part that is usually eaten as part of a meal" (Oxford English Dictionary, 2018).

- Usual fruit and vegetable intake: Measured by the Behavioral Risk Factor Surveillance Survey Fruit and Vegetable Module, a six-item self-report questionnaire that measures the frequency of fruits and vegetables consumed over the past 30 days (Centers for Disease Control and Prevention, 2011).

- The operational definition of fruit and vegetable attitude: The measure, "For me, eating at least four and a half servings of fruits and vegetables per day is" (harmful or beneficial on a Likert scale) (Francis et al., 2004).

- The operational definition of fruit and vegetable perceived behavioral control: The measure of how much control the individual has over fruit and vegetable intake and how confident the individual feels about being able to consume or not consume fruit and vegetables (on a Likert scale) (Francis et al., 2004).

- The operational definition of fruit and vegetable intention: The measure of the individual's expectation, desire, and motivation to consume fruit and vegetables (on a Likert scale) (Francis et al., 2004).

\section{Method}

A quantitative study using a convenience sample of community dwelling residents in rural West Virginia was conducted to answer the research questions. Participants were recruited 
from community gatherings, local shopping centers, diabetes prevention programs, and community health fairs; inclusion and exclusion criteria guided the recruitment. Consented participants completed three surveys: demographic, fruit and vegetable intake, and theory of planned behavior questionnaire. Demographics were used to describe the sample. Predictive relationships were examined using the fruit and vegetable intake and theory of planned behavior questionnaire mean scores. The theory of planned behavior questionnaire has been demonstrated to be a reliable and valid measure of attitude, perceived behavioral control, and intention in other fields. Cronbach alpha analyses on the theory of planned behavior questionnaire direct measures were conducted to establish internal consistency $(>0.6)$. The relationship of attitude, perceived behavioral control, and intention in the subjects were examined based on fruit and vegetable intake scores obtained through the theory of planned behavior questionnaire administered to residents with pre-diabetes who live in rural West Virginia.

\section{Summary}

Pre-diabetes is a precursor to the chronic disease of diabetes which negatively impacts those who have it. People with pre-diabetes are more likely to be diagnosed with diabetes within five years if they do not make lifestyle changes. Lifestyle changes can reduce the risk of developing diabetes by 58\%. This includes fruit and vegetable intake. Knowledge of associated variables of fruit and vegetable intake in a rural population of West Virginia residents with prediabetes may assist in more effective interventions aimed at decreasing the risk for type 2 diabetes in this population. 


\section{Chapter 2: Review of the Literature}

The purpose of this study is to identify the association between fruit and vegetable attitude, perceived behavior control, and intention and fruit and vegetable intake. A review of the literature was conducted to examine current research on fruit and vegetable intake and prediabetes, predictor variables associated with fruit and vegetable intake, and the use of the theory of planned behavior (Ajzen, 2005) as a theoretical framework for study in this area. The search results concentrated on the following search terms: diabetes prevention, pre-diabetes, fruit and vegetable intake, and predictors of fruit and vegetables.

\section{Literature Search Process}

EBSCOhost was used to search CINAHL, MEDLINE, PsycARTICLES, and PsycINFO databases with the search terms diabetes prevention, pre-diabetes, fruits and vegetables, and predictors of fruit and vegetables. The initial search resulted in 514 articles. After adding the following search limits, including English language, adult age, and date restricted to 2012 to present, 418 articles were excluded. The resulting 96 articles were eligible for inclusion if they met the following criteria: adult population, had a component of fruit and vegetable intake or a component of predictor variable for fruit and vegetable intake, and involved the prevention of diabetes. Of the 96 studies, 82 were excluded because they did not meet inclusion criteria after full text screening. Four articles were excluded during data extraction, for a final total of ten studies included for this review (see Figure 1). The studies were quantitative and descriptive in nature. They were conducted in the United States, and one each in England, Iran, and Japan. There were no qualitative research articles included in this review. This review revealed a gap in the literature concerning associations of fruit and vegetable intake among adults with prediabetes. 


\section{Literature Review}

The first focus of the literature review was on the inverse relationship between fruit and vegetable intake and pre-diabetes. The second focus was on interventions aimed at decreasing the risk for type 2 diabetes in individuals with pre-diabetes by increasing the individual's consumption of fruit and vegetables. The final focus concentrated on predictors of fruit and vegetable intake within intervention programs for the prevention of diabetes. The literature review was organized based on type of study (intervention, secondary analysis, case control, or predictor). The review findings revealed a gap in the literature related to fruit and vegetable attitude, perceived behavioral control, intention, and intake. In addition, the findings indicated that the theory of planned behavior provides theoretical underpinnings for this proposed dissertation study.

Intervention studies. Kanaya et al. (2012) conducted a randomized controlled trial to evaluate the adaptation of a community-based lifestyle intervention (Live Well Be Well Program) aimed at reducing the risk for diabetes in lower-socioeconomic status and ethnic minority adults. The sample $(N=238)$ consisted of community-dwelling adults in four lowincome neighborhoods in California. Primary outcomes (fasting blood glucose, triglycerides, high density lipoprotein, low density lipoprotein, weight, waist circumference, and systolic blood pressure) and secondary outcomes (diet [fruit and vegetable intake], physical activity, and health related quality of life) were measured at six and 12 months. This study revealed a statistically significant difference in frequency of fruit and vegetable intake between intervention and control groups at both six $(p=.02)$ and twelve months $(p=.04)$. Group differences at six months were significant for weight loss $(p=.03)$, decreased triglycerides $(p=.02)$, and increased fruit and vegetable intake $(p=.02)$. This study found that an intervention for decreasing risk for diabetes 
adapted for lower-socioeconomic status and ethnic minorities was still effective for lowering key factors for diabetes prevention.

Condrasky et al. (2013) conducted a group randomized study to examine whether demographic, health related, and psychosocial variables at baseline predicted an increase in fruit and vegetable intake from baseline to post program. The program was a 15-month, faith-based, physical activity and dietary intervention. The demographic and health-related variables collected by self-report included age, gender, race, marital status, total household income, highest grade or years of education completed, and rate of general health status on a scale, number of times they attend worship services, and church activities or meetings. The sample consisted of 1,257 faith-based African Americans in 74 African Methodist Episcopal churches in South Carolina. The findings demonstrated a higher post-test fruit and vegetable consumption after controlling for pre-test values in those who had a greater waist circumference $(p=.04)$, greater baseline fruit and vegetable consumption $(p<.0001)$, greater leisure-time physical activity $(p=.01)$, greater social support $(p=.01)$, higher worship service attendance $(p=.04)$, were obese $(p=.04)$, and those without the diagnosis of diabetes $(p=.03)$.

Kieffer et al. (2014) conducted an intervention study to evaluate the effectiveness of a community-based healthy lifestyle intervention (Mothers on the Move) designed to improve dietary habits in pregnant Latinas in Detroit, Michigan. The sample $(N=275)$ consisted of pregnant women recruited from a federally qualified health center, Women/Infants/Children (WIC) program, and community organizations. Outcome variables included added sugars, total fat grams, saturated fats, fiber, fruits, and vegetables. Post intervention, the intervention group showed significant improvement in all dietary behaviors except fruit intake. There were no significant findings regarding increase in fruit intake in the study, however this may be due to the 
relatively high baseline fruit intake. The researchers found a statistically significant difference in vegetable intake between the groups, with the intervention group having a $41.9 \%$ greater increase in vegetable intake than the control group. The intervention group showed a significantly decreased intake of added sugar $(p=.05)$, total fat grams $(p<.05)$, and saturated fats $(p<.01)$, and increased intake of fiber $(p<.05)$ and vegetables $(p<.001)$.

All three of the intervention studies found evidence to support the effectiveness of the tested interventions in increasing fruit and vegetable intake (Condrasky et al., 2013; Kanaya et al., 2012; Kieffer et al., 2014). This suggests that intervention programs have a positive impact on participants' dietary behaviors concerning fruit and vegetable intake and offer support that knowledge of associations (Condrasky et al., 2013) of fruit and vegetable intake may help nurses to tailor interventions to target behaviors that would assist participants in adhering to fruit and vegetable intake. This is important because diabetes prevention efforts are targeted at community-based interventions aimed at altering a participant's weight, physical activity, and dietary habits. Since the diabetes prevention program is designed to be a one-year program that teaches participants skills to enact lifestyle changes and implement these changes without the support of the program, effective interventions and predictors of fruit and vegetable intake may be very important components to ensure the impact of lifestyle changes on diet and subsequent health.

Secondary data analyses. Kurotani et al. (2013) conducted a prospective cohort study to investigate the risk of type 2 diabetes in relation to fruit and vegetable intake in a large-scale, population-based cohort of Japanese men and women and examined the association with specific subgroups of fruits and vegetables. The sample consisted of 48,437 Japanese men and women. Variables included fruit and vegetable intake, diagnosis of type 2 diabetes, smoking status, 
alcohol consumption, leisure-time activity, history of hypertension, family history of diabetes, coffee consumption, total energy intake, calcium intake, and magnesium intake. Although the combination of fruit and vegetable intake or intake of fruit alone was not associated with a lower risk of type 2 diabetes, there was a nonsignificant risk reduction associated with vegetables (OR $0.81[0.59-1.13])$ and cruciferous vegetables (OR 0.78 [0.58-1.06]) in men, and green leafy vegetables in both men (OR 0.83 [0.62-1.12]) and women (OR 0.81 [0.57-1.16]).

Cooper et al. (2015) conducted a prospective study to evaluate the association between the quantity and variety of fruit, vegetable, and combined fruit and vegetable consumption and the incident of type 2 diabetes. The sample $(N=3,704)$ was a random sub-cohort from within a larger study (EPIC-NORFOLK). Variables included educational level, occupational social class, smoking status, baseline history of myocardial infarction, cerebral vascular accident, cancer, area of deprivation, physical activity, height, weight, waist circumference, and body mass index. Findings included that: a greater quantity of fruit and vegetable intake was significantly associated with a $21 \%$ lower hazard of type 2 diabetes (OR 0.79 [0.62-1.00]); quantity of vegetable intake was inversely associated with type 2 diabetes (OR 0.76 [0.60-0.97]); and greater variety in fruit (OR 0.70 [0.53-0.91]), vegetable (OR 0.77 [0.61-0.98]), and combined fruit and vegetable (OR 0.61 [0.48-0.78]) was associated with lower hazard risk for type 2 diabetes.

In these studies, an inverse association between quantity of fruit, vegetable, and combined fruit and vegetable intake $(p=.60)$ and type 2 diabetes was revealed, supporting the need for increased fruit and vegetable intake in individuals with pre-diabetes (Cooper et al 2015; Kurotani et al., 2013). Cooper et al. (2015) also revealed that less than $26 \%$ of the study's participants reported consuming the recommended five or more servings of fruits and vegetables per day, only $50 \%$ reported meeting the recommended quantity (three to five portions of fruit and 
vegetables per day), and only $40 \%$ reported consuming the recommended variety (12 different fruit and vegetable items per week), supporting the need for the identification of associations of fruit and vegetable intake so that interventions and education can be tailored to address the specific construct that affects fruit and vegetable intake. Further investigation is needed in fruit and vegetable intake across differing cultures, since the authors state the lack of significant findings could be related to dietary habits already high in fruits and vegetables at baseline. One of the studies was conducted among men and women in Japan, who tend to have different dietary intake patterns than men and women in the United States. A correlation between an increase in fruit and vegetable intake and decrease in pre-diabetes and incidence of type 2 diabetes was found in each of the studies and suggested that fruit and vegetable intake is a key component in reducing the incidence of type 2 diabetes.

Case-control study. Safabakhsh et al. (2017) conducted a case-control study to determine the relationship between the consumption of fruit and vegetables, their specific subgroups, and pre-diabetes. The sample $(N=300)$ included subjects recruited from a diabetes screening center in Shahreza, Iran. The variables included sex, age, education level, body mass index, waist circumference, physical activity, dietary supplement use, energy intake, healthy eating index, fast blood glucose, two-hour glucose, and fruit and vegetable intake. Results of the study indicated that participants in lower quartiles of fruit and vegetable intake and total fruit intake were more likely to experience pre-diabetes than participants in the higher quartiles $(p$ trend $<0.007$ ); cruciferous vegetables, other vegetables, and berries were inversely associated with pre-diabetes $(p<0.05)$; and higher intake of dark yellow vegetables was significantly associated with pre-diabetes $(p$ trend $=0.006)$. 
The participants who had a lower intake of fruit and vegetables and total fruit were more likely to experience pre-diabetes compared to participants with higher intakes of fruit and vegetables, suggesting the protective nature of fruits and vegetables in pre-diabetes. Further, the study also revealed specific subgroups of fruit and vegetables, such as cruciferous vegetables, other vegetables, and berries, that were inversely associated with pre-diabetes. This protective nature of fruits and vegetables against pre-diabetes supports the need to know more about variables that will predict intention of adults with pre-diabetes to consume or not consume fruits and vegetables and may offer information that may be used to address resistance to fruit and vegetable intake.

Predictor studies. Godinho et al. (2014) conducted a longitudinal study to investigate volitional predictors of change in the daily consumption of fruit and vegetables. The sample $(N$ $=203$ ) was comprised of university students recruited from three universities. Variables included outcome expectations, perceived self-efficacy, intention, coping planning, action control, and fruit and vegetable intake. The study results indicated that coping planning and action control (volitional factors) were sequential mediators between intention and behavior.

Kothe and Mullan (2014) conducted a secondary data analysis across three prospective cohorts to investigate the application of the theory of planned behavior to the prediction of fruit and vegetable consumption. The sample $(N=386)$ consisted of undergraduate students enrolled in a first-year psychology course at an Australian university. Variables included attitude, subjective norm, perceived behavioral control, intention, and fruit and vegetable intake. The findings indicated that: attitude moderated the impact of perceived behavioral control on intention; and that perceived behavioral control moderated the impact of intention on behavior at one week but not at one month. 
Evans et al. (2015) conducted a prospective study to investigate the utility of behavioral resolve in measuring motivation to comply with fruit and vegetable intake recommendations. The sample $(N=139)$ consisted of United Kingdom university students. The variables measured were demographic (age, gender, nationality, living conditions, and dietary status); predictors of fruit and vegetable intake (intention, behavioral resolve, action planning, and coping planning); fruit and vegetable consumption; and perceived barriers to fruit and vegetable intake. The findings showed that predictor variables were significantly correlated $(p<.001)$ with fruit and vegetable intake, and that intention and behavioral resolve were significant predictors of fruit and vegetable intake. However, behavioral resolve (40.1\%) explained greater fruit and vegetable intake variance than intention $(36.4 \%)$.

Tomasone et al. (2015) conducted a descriptive study to examine independent and combined effects of the theory of planned behavior variables and trait self-control in the prediction of fruit and vegetable intake among university students. The sample consisted of 76 first-year undergraduate university students. Variables included demographic (age, sex, ethnicity, program of study, date of high school graduation, and current hours of class time); theory of planned behavior concepts (attitude, subjective norm, perceived behavioral control, and intention); fruit and vegetable consumption; and trait self-control. The findings demonstrated that baseline attitude and perceived behavioral control predicted intention (adj $\left.R^{2}=.58\right)$ and that intention and trait self-control predicted fruit and vegetable consumption $\left(\operatorname{adj} R^{2}=.24\right)$.

The predictor studies in this review were examined to investigate findings regarding predictors of fruit and vegetable intake in adults. None of the literature focused on predictors of fruit in adults with prediabetes, despite the association of the protective role of fruits and vegetables in diabetes prevention (Cooper et al., 2015; Safabakhsh et al., 2017). All four studies 
were conducted on the college student population (Evans et al., 2015; Godinho et al., 2014;

Kothe \& Mullan, 2015; Tomasone et al., 2015).

The findings illustrate that volitional factors, including action control and coping planning, reflect a psychological mechanism that contributes to change in fruit and vegetable intake behavior (Godinho et al., 2014). This suggests that the theory of planned behavior is a valid model for addressing volitional factors by way of perceived behavioral control. Individuals who are motivated, but not yet meeting the recommendations for fruit and vegetable intake, may be influenced by motivational mechanisms designed to affect fruit and vegetable intake. Both intention and behavioral resolve were significant predictors of fruit and vegetable intake with behavioral resolve having an additive effect on intention, suggesting the higher likelihood that a behavior performed will be influenced by the intention to perform the behavior (Evans et al., 2015). Since intention moderates the relationship between perceived behavioral control and behavior and there was no significant relationship between perceived behavioral control and behavior when intention is low, this finding suggests that interventions that do not consider intention may be less effective when trying to increase perceived behavioral control (Kothe \& Mullan, 2015). Likewise, both attitude and perceived behavioral control were statistically significant predictors of intention to consume fruits and vegetables and accounted for 58 percent of the variance. This suggests that positive feelings toward fruit and vegetable intake and the perception that fruit and vegetable intake is both beneficial and achievable promotes stronger intention to participate in fruit and vegetable intake (Tomasone et al., 2015).

\section{Summary}

Based on the knowledge that fruit and vegetable intake is associated with a decrease in pre-diabetes and incidence of type 2 diabetes, study of predictors of fruit and vegetable intake 
guided by the theory of planned behavior (Ajzen, 1991) is warranted and may subsequently be utilized to effectively develop interventions aimed at decreasing pre-diabetes. Knowledge of predictor variables may aid in how we approach individuals and tailor interventions. West Virginian adults have been reported to engage in unhealthy dietary behaviors. According to the CDC (2017), only one in four adults $(25.3 \%)$ consumed fruits at the recommended level (2 or more times/day) and only $22.1 \%$ reported recommended levels of vegetable consumption (3 or more times/day). West Virginia ranks number one in prevalence for diabetes (CDC, 2017). About half of the adults with pre-diabetes will develop diabetes within 10 years (University of Pittsburgh, 2018). Since there is documented evidence that fruit and vegetable intake reduces the risk of pre-diabetes, an examination of fruit and vegetable intake among adults with pre-diabetes and factors associated with fruit and vegetable intake among rural West Virginian residents with pre-diabetes is warranted.

This chapter provided an overview of the literature review process and a synthesis of the theoretical, methodological, and empirical underpinnings for the proposed study. Research related to fruit and vegetable intake among individuals with pre-diabetes was synthesized. Robust evidence on reduction in risk of type 2 diabetes due to fruit and vegetable intake in the general population was examined. Adults consuming recommended levels of fruit and vegetable intake and pre-diabetes were less likely to develop type 2 diabetes. Many patient-level factors, including demographics, attitude, intention, knowledge, and behavior control, were associated with fruit and vegetable intake. However, no studies examined the factors associated with fruit and vegetable intake in among rural West Virginian residents with pre-diabetes. Such a study is important because of the specific circumstances West Virginian adults face, such as poverty, rurality, and accessibility to fresh fruits and vegetables. 
Therefore, this investigator proposes a cross-sectional survey to elicit factors associated with and predictive of fruit and vegetable intake among rural West Virginian residents with prediabetes. The focus will include only those with pre-diabetes rather than the general population with and without diabetes. It is known that $50 \%$ of adults with pre-diabetes are likely to develop diabetes within 10 years (University of Pittsburgh, 2018). Any prevention effort to postpone the onset of type 2 diabetes or prevent type 2 diabetes will improve the health-related quality of life and will reduce cost of care. In West Virginia, 107,896 adults have pre-diabetes; a 58\% reduction in type 2 diabetes (Centers for Disease Control and Prevention, 2016) will save \$1,112 dollars per capita in terms of Medicaid, private insurance, and out-of-pocket spending by patients and families (National Association of Chronic Disease Directors, n.d.). With noted gaps in the literature, support for examining predictors of fruit and vegetable intake among rural West Virginian residents with pre-diabetes is evident. 


\section{Chapter 3: Method}

The purpose of this study was to examine the relationships among fruit and vegetable attitude, perceived behavior control, intention, and intake among rural West Virginia residents with pre-diabetes. To answer the four research questions, a feasibility descriptive study was conducted to examine the relationship between fruit and vegetable attitude, perceived behavioral control, and intention with fruit and vegetable intake among adults with pre-diabetes living in West Virginia. The method was guided by the theory of planned behavior (Ajzen, 2005). Associations of fruit and vegetable intake, including fruit and vegetable attitude, fruit and vegetable perceived behavioral control, and fruit and vegetable intention, were measured using a theory of planned behavior questionnaire.

Pre-diabetes is more prevalent among adults living in West Virginia than adults living in many other states in the United States, therefore, it is important to identify associations of fruit and vegetable intake of West Virginian adults to target diabetes prevention interventions. According to Ajzen's (2005) theory of planned behavior, used as theoretical framework for this study, fruit and vegetable intention is a direct antecedent to fruit and vegetable intake behavior (see Figure 2).

\section{Procedure for Data Collection: Investigator and Research Assistant}

The investigator was responsible for the coordination of study components including the organization of the study protocol, overseeing the entire study, obtaining letters of support for the research study from sites of data collection, training one research assistant who is a Certified Diabetes Educator (CDE), collecting data from questionnaires, checking the fidelity of the study, and entering and analyzing data. The investigator who conducted this study is a master's prepared, advanced practice registered nurse working on her Doctor of Philosophy $(\mathrm{PhD})$ degree 
in nursing research. Her previous experience includes nine years of professional nursing in areas of acute care in a critical access hospital and four years in family practice. She has worked with many patients with pre-diabetes and diabetes, and is a diabetes prevention program coach. The research assistant is a master's prepared nurse. She has been a registered nurse for 23 years, a $\mathrm{CDE}$ for four years, and is a diabetes prevention program coach who is also certified to train others to be a diabetes prevention program coach. See Table 1 for the research protocol for this study.

\section{Approach and Study Design}

A feasibility design with survey methods was used to achieve the study aims. Data was collected using demographic, theory of planned behavior, and fruit and vegetable intake questionnaires. See Table 1 for the study protocol.

\section{Recruitment}

A convenience sample of rural West Virginian residents with pre-diabetes was studied. Participants were recruited from community settings. Flyers about the study were distributed at community gatherings, fairs, events, churches, and malls/shopping centers. To be eligible, participants were aged 18 or over, have pre-diabetes, and reside in West Virginia.

\section{Sampling Plan}

A feasibility, convenience sample was collected to study adults with pre-diabetes who reside in West Virginia. The target population was adults in West Virginia screened at community gatherings, fairs, events, churches, and malls/shopping centers. To have met the definition of pre-diabetes, participants must of had a score of nine or higher on the CDC risk test for pre-diabetes or reported a history of gestational diabetes. Based on clinical knowledge of the 
population served within the community, a representative sample of residents with pre-diabetes living in rural West Virginia was recruited.

Sample size was determined using the Tabachnick and Fidell (2007) guideline of $n>50$

$+8 \mathrm{k}$, where $\mathrm{n}$ equals the sample size and $\mathrm{k}$ equals the number of predictors; in this study of fruit and vegetable intake, there were three predictors. Following this rule, this study required a sample size of 74 participants. Based on the number of adults with pre-diabetes served within the study sites, the sample size appeared to be attainable. The study was pilot tested with ten participants initially. The following criteria was used to guide recruitment and delimitation of the accessible population of participants:

Inclusion criteria:

- Age 18 or older

- Able to read, understand, write, and speak English

- Meets definition of pre-diabetes (CDC risk assessment of nine or greater or selfreports history of gestational diabetes)

- Provides informed consent

- Resides in West Virginia

Exclusion criteria

- Diagnosis of cognitive or mental impairment (self-report)

- Diagnosis of diabetes

- Pregnant

- On special diet

- On blood thinner

Once a potential participant was approached within the community setting introduction to the study commenced. Upon discussion with the potential participant, inclusion and exclusion criteria was confirmed. At this time, the CDC risk assessment was used to determine if the potential participant met the definition for pre-diabetes. The CDC risk test assesses the participant's risk for pre-diabetes by asking a series of seven questions (National Center for Chronic Disease Prevention and Health Promotion, n.d.). For every "yes" answer a number value is given. All "no" answers are given a value of zero. At the end of the questions all yes answers 
with corresponding numbers are totaled. If a participant scores a nine or higher, they are considered to be at risk for pre-diabetes.

If the definition and criteria were fully met and the participant volunteered to participate in the study, informed consent was obtained. Upon informed consent, demographic, fruit and vegetable intake, and theory of planned behavior questionnaire survey data were collected from the participant. Measurements for secondary outcomes (height, weight, body mass index, and waist circumference) were obtained by the researcher if not available from the participant's health record or primary care provider.

\section{Instrumentation}

Demographic survey. Participant demographics were collected using a survey requesting age, gender, marital status, county of residence, state of residence, education level, total household income level, ethnicity, and race. Height, weight, body mass index, and waist circumference were obtained from the participant's medical record or primary care provider (or were measured/calculated by the investigator if data was not available).

Fruit and vegetable intake questionnaire. Fruit and vegetable intake was measured by the Behavioral Risk Factor Surveillance Survey (BRFSS) Fruit and Vegetable Module, a sixitem self-report questionnaire that measures the frequency of fruits and vegetables consumed over the past 30 days (Centers for Disease Control and Prevention, 2011). The fruit and vegetable intake questionnaire consists of six questions; four of the six questions classify fruit and vegetables according to subgroups recommended for chronic disease prevention (Centers for Disease Control and Prevention, n.d.). The 1989-2009 module has been compared to longer food questionnaires, diet records, and 24-hour diet recalls, with correlations ranging from 0.47 to 
0.0.63 (Smith-Warner et al., 1997; Willet \& Lenart, 1998). According to Nelson et al. (2001), the module has moderate reliability measured by correlation coefficients ranging from 0.33 to 0.77 . Fruit and vegetable intake were assessed with the following six questions:

- During the past month, how many times per day, week or month did you drink $100 \%$ PURE fruit juices? Do not include fruit-flavored drinks with added sugar or fruit juice you made at home and added sugar to. Only include $100 \%$ juice.

- During the past month, not counting juice, how many times per day, week, or month did you eat fruit? Count fresh, frozen, or canned fruit.

- During the past month, how many times per day, week, or month did you eat cooked or canned beans, such as refried, baked, black, garbanzo beans, beans in soup, soybeans, edamame, tofu, or lentils. Do NOT include long green beans.

- During the past month, how many times per day, week, or month did you eat dark green vegetables, for example broccoli or dark leafy greens including romaine, chard, collard greens, or spinach?

- During the past month, how many times per day, week, or month did you eat orangecolored vegetables, such as sweet potatoes, pumpkin, winter squash, or carrots?

- Not counting what you just told me about, during the past month, about how many times per day, week, or month did you eat OTHER vegetables? Examples of other vegetables include tomatoes, tomato juice or V-8 juice, corn, eggplant, peas, lettuce, cabbage, and white potatoes that are not fried such as baked or mashed potatoes.

Theory of Planned Behavior questionnaire. The theory of planned behavior questionnaire is designed to predict behavior by measuring the theoretical concepts (attitude, perceived behavioral control, and intention) and fruit and vegetable intake (see Appendix A). The questions are designed to measure the individual's attitude and beliefs underlying fruit and vegetable intake. Francis et al. (2004) developed a manual for researchers in health services to aide in the construction of questionnaires based on the theory of planned behavior; using their manual, a direct-measure questionnaire was adapted. The theory of planned behavior questionnaire has demonstrated adequate reliability and validity in other populations. In a study examining the validation of a theory of planned behavior questionnaire used to examine factors 
associated with milk expression in college students, the Cronbach's alpha for the theory concepts was .78 (Bai \& Dinour, 2017). Another study examining a theory of planned behavior questionnaire focusing on foot care in individuals with diabetes reported a Cronbach's alpha of $>$ 0.70 in all four concepts (Aparecida Monteiro et al., 2015).

\section{Conceptual and Operational Definitions of Variables}

Fruit and vegetable intake attitude is the individual's overall evaluation of the behavior. Fruit and vegetable intake attitude includes beliefs about consequences of fruit and vegetable intake and the corresponding positive or negative judgments about each of these features of fruit and vegetable intake. The participant is asked to rate on a Likert-type scale four separate questions that all begin with "For me, eating at least four-and-a-half servings of fruits and vegetables per day is" and the respondent selects between harmful/beneficial; good/bad; pleasant/unpleasant; and worthless/useful.

Fruit and vegetable perceived behavioral control is the individual's confidence in the capability of performing fruit and vegetable intake. Fruit and vegetable perceived behavioral control includes the individual's self-efficacy and beliefs about the controllability of fruit and vegetable intake. Self-efficacy is measured by asking the participant to rate on a Likert-type scale the following two questions: "I am confident that I could eat at least four-and-a-half servings of fruits and vegetables per day if I wanted to (Strongly disagree/Strongly agree)" and "For me to eat at least four-and-a-half servings of fruits and vegetables per day is (Easy/ Difficult)." Controllability is measured by asking the participant to rate on a Likert-type scale the following two questions: "The decision to eat at least four-and-a-half servings of fruits and vegetables per day is beyond my control (Strongly disagree/Strongly agree)" and "Whether I eat 
at least four-and-a-half servings of fruits and vegetables per day is entirely up to me (Strongly disagree/Strongly agree).”

Fruit and vegetable intention is an individual's motivation or decision to consume fruit and vegetable intake. Fruit and vegetable intention is determined by the individual's attitude and perceived behavioral control. Fruit and vegetable intention will be measured by asking participants to rate, on a Likert-type scale, three statements: "I expect to eat at least four-and-ahalf servings of fruits and vegetables per day," "I want to eat at least four-and-a-half servings of fruits and vegetables per day," and "I intend to eat at least four-and-a-half servings of fruits and vegetables per day." Reliability using Cronbach's alpha testing will be conducted.

\section{Data Collection}

The data collection process began with contact at public places within the community or by self-referral. Potential participants were prescreened to ensure that they met the inclusion/exclusion criteria. If the participant met the criteria, a consent form was reviewed with him/her. Biophysical measures (weight, height, BMI, and waist circumference) were obtained as needed (if not available in the medical record or from the PCP). The timeframe for data collection for 74 participants was expected to span over three months.

\section{Data Analysis}

Univariate analyses on the demographic data and bivariate analyses, using chi-square and $t$-tests, were conducted to describe the sample. The main research questions were answered using standard multiple regression. SPSS software was used to analyze data. Alpha was set at .05 for all analyses.

To answer the main questions (regression model), analyses was conducted using the direct measures of the variables. An analysis on the items of direct measure was conducted to 
establish internal consistency. If the internal consistency of all coefficients was acceptable then it was appropriate to include all items in the composite variables. The next step was to create composite variables for the direct measures, with recoding for negatively-worded items, and calculating means as proposed by Francis et al. (2004). The new variables were defined clearly so that variable labels were included in output files, and the regression model was developed using the final variables (fruit and vegetable attitude, perceived behavioral control, and intention, each with fruit and vegetable intake). Usual fruit and vegetable intake was entered as the dependent variable and the direct measures of fruit and vegetable attitude, fruit and vegetable perceived behavioral control, and fruit and vegetable intention were entered as independent variables.

\section{Human Rights and Ethical Considerations}

The study proposal was submitted to WVU Institutional Review Board for ethical review and consideration of the protection of human participants. This research study qualified for exempt research category two because it is research involving survey procedures and a copy of survey questions was attached on the notes and attachment page. All participants meeting the inclusion and exclusion criteria were provided an opportunity to voluntarily participate in the study. Informed consent was reviewed with the participants by the nurse investigator and any questions were addressed and answered prior to the verbalizing of consent to participate. Confidentiality of the participants' information was protected and maintained by de-identifying all data (coded to the participant through a random number generator) and by maintaining data password-protected on a computer and locked in a filing cabinet accessible only by the nurse investigator. A copy of the informed consent was provided to the participant. 
There were benefits and minimal risks to individuals participating in this study. The benefits of participating in the study include helping others to understand associations of fruit and vegetable intake of West Virginian adults with prediabetes. In addition, the results may inform further work in the development of interventions to decrease the risk of pre-diabetes. Benefits outweigh the minimal risks associated with participation. Since this is not an intervention study, there may be no direct benefit to participants. The risks of participating in the study may include invasion of privacy and stress in relation to feelings of guilt, shame, or embarrassment related to dietary habits.

\section{Methods to Assure Rigor}

Several methods were used to assure rigor of this research study. The investigator implemented strict adherence to inclusion and exclusion criteria, set alpha at .05 for analyses, and recruit a pilot sample of 10 and a final sample of at least 74 participants to promote adequate statistical power and medium effect size. In addition, the investigator used instruments with adequate reliability and validity (as reported in previous studies). Both the investigator and research assistant who conducted the study have experience with pre-diabetes, diabetes, diabetes prevention, and understanding of the criteria.

\section{Feasibility of Research}

This research study was feasible because of the investigator's working relationship with administrators at the proposed study sites, good rapport with community members, and affiliation with local health fairs in the community. The research entailed the recruitment and collection of data from West Virginian individuals with pre-diabetes who live, work, and/or play within the community. Permission to conduct the proposed research study was obtained from 
administrators within each facility. Financial compensation (\$25 gift card) was provided to each participant upon his/her completion of the study.

\section{Summary}

A study designed to identify variables, especially fruit and vegetable attitude, perceived behavioral control, and intention, that may reveal associations of fruit and vegetable intake behavior was proposed. The methods used to conduct the study, including recruitment processes, instrumentation, data collection, and analyses, were summarized. The findings of the proposed study may encourage clinicians and nurses to focus on components of interventions aimed at pre-diabetes risk reduction and subsequent diabetes prevention. This will allow for the greatest impact on prevention among adults with pre-diabetes in West Virginia. The study

results may help identify which variable is most likely to impact fruit and vegetable intake and future interventions. 


\section{Chapter 4: Results}

This study was conducted to examine the association of fruit and vegetable attitude, fruit and vegetable perceived behavioral control, fruit and vegetable intention to usual fruit and vegetable intake in adults with prediabetes. A complete description of the data collection process, data cleaning and coding, and analysis results are provided in this chapter.

\section{Pilot Study}

A pilot study was conducted to evaluate the feasibility of recruitment and to assess the effectiveness of fruit and vegetable intake questionnaire in capturing perception and intake of the study. All recruitment procedures complied with WVU IRB and HIPAA guidelines A total of 13 subjects were screened for prediabetes using the CDC risk test for pre-diabetes (Center for Disease Control and Prevention, n.d.). We screened 13 individuals for eligibility. The eligibility criteria were: participants had to be 18 years or older, be able to read, write and speak English, have prediabetes, provide informed consent and reside in West Virginia. Participants were excluded if they self-reported physician diagnosed cognitive impairment or diabetes, were pregnant, on a special diet or taking blood thinners since participants may have altered their intake of vegetables associated with effectiveness of blood thinning medications.

Out of the 13 screened, 10 met the inclusion and exclusion criteria for the study and all ten individuals agreed to participate. These ten subjects were recruited within one setting at a community event held at a church in Mineral county. To meet the inclusion criteria, Participants were also asked six questions (please see Appendix B) about the ambiguity, difficulty, length, repetitiveness, and whether the questions were superficial. The questions were formatted for yes or no responses. Each question had space available for additional comments or further explanation. The participants unanimously reported that there were not any items 
ambiguous or difficult to answer, and that the questionnaire did not feel too repetitive, too long, or too superficial. The participants also unanimously reported that there were not any annoying features of the wording or formatting or inconsistent responses that might indicate that changes in response endpoints are problematic for respondents who complete the questionnaire quickly. Participants were asked if they had any other comments or questions and all respondents reported they had no questions about the study questionnaire outside of the verbal instructions given for completion. Participants answered all questions. There were no additional comments made by the participants.

The questionnaires were filled out within the expected twenty-minute timeframe. There were no additional questions asked for clarity of questions. The pilot study confirmed that the study is both feasible and acceptable to WV residents. After completion of the pilot study, data collection for the main study began.

\section{Power and Sample Size}

The formula developed by Tabachnick and Fidell (2007) was used to calculate the sample size at power 0.80 . The calculations $(50+8 *$ number of independent variables $)$ yielded a sample size of 74 to test the associations of 3 independent variables.

\section{Recruitment of Subjects}

For the present study, subjects were recruited and screened during community events and gatherings. Permission to recruit was granted by WVU Medicine Potomac Valley Hospital, Potomac State College, Walmart, Family Resource Network, Cross Independent Church, Romney Moose, and Hampshire Wellness and Fitness. Recruitment began on January 9, 2019 and was completed on January 23, 2019. Overall, 94 subjects were screened for the presence of pre-diabetes using the CDC risk test from communities of Hampshire and Mineral County. Of 
the 94 individuals screened in the community, 74 were positive for having pre-diabetes and met the inclusion and exclusion criteria for the study. All 74 individuals agreed to participate. Recruitment ended with the desired sample size of 74 . The individuals were recruited from two counties in West Virginia (Hampshire, $n=13$; Mineral, $n=61$ ). West Virginia residency was established by asking the question assessing "Are you currently a West Virginia resident?" Measurement levels were yes and no.

\section{Data Collection and Management}

Data were collected using paper/pencil versions of the survey questionnaire. Responses from these questionnaires were subsequently entered the Statistical Package of Social Sciences (SPSS) program for data analysis (IBM, 2017). Data were stored on computer that is password protected and hard-copy surveys were protected in a locked filing cabinet, in a locked office. Data were checked for missing items, outliers, and by analyzing frequencies. There were no missing data on any variable. Outliers were found in age; their data were verified as correct by verification of the data by verbal contact with the participant and thus was included in the analysis.

\section{Measures}

\section{Dependent Variable: Usual Fruit and Vegetable Intake}

Usual fruit and vegetable intake was measured by a six item self-report questionnaire. This questionnaire measured the frequency of fruit and vegetable consumption over the previous 30 days. This questionnaire was chosen because of the low response burden and was used by the BRFSS. This instrument has been shown to be valid and reliable and able to detect populationlevel change (Nelson et al., 2001). 


\section{Key Independent Variables}

Fruit and vegetable attitude, fruit and vegetable perceived behavioral control, and fruit and vegetable intention were measured by a Likert-type scale with responses coded from 1 to 7 ; higher values on these scales represent better attitude, control, and intention. As each measure consisted of seven items, we averaged the scores over the items to derive average scores for attitude towards vegetable intake, perceived behavioral control and intention to take fruitvegetable intake.

\section{Attitude toward usual fruit and vegetable intake}

The fruit and vegetable attitude is the measure of the individual's overall evaluation of the behavior. Fruit and vegetable attitude includes beliefs about consequences of fruit and vegetable intake and the corresponding positive or negative judgments about each of these features of fruit and vegetable intake. The participant is asked to rate on a Likert-type scale four separate questions that all begin with "For me, eating at least four-and-a-half servings of fruits and vegetables per day is" and the respondent selects between harmful/beneficial; good/bad; pleasant/unpleasant; and worthless/useful.

\section{Perceived behavioral control to usual fruit and vegetable intake}

Fruit and vegetable perceived behavioral control is the individual's confidence in the capability of performing fruit and vegetable intake. Fruit and vegetable perceived behavioral control includes the individual's self-efficacy and beliefs about the controllability of usual fruit and vegetable intake. Self-efficacy is measured by asking the participant to rate on a Likert-type scale the following two questions: "I am confident that I could eat at least four-and-a-half servings of fruits and vegetables per day if I wanted to (Strongly disagree/Strongly agree)" and "For me to eat at least four-and-a-half servings of fruits and vegetables per day is (Easy/ 
Difficult)." Controllability is measured by asking the participant to rate on a Likert-type scale the following two questions: "The decision to eat at least four-and-a-half servings of fruits and vegetables per day is beyond my control (Strongly disagree/Strongly agree)" and "Whether I eat at least four-and-a-half servings of fruits and vegetables per day is entirely up to me (Strongly disagree/Strongly agree).”

\section{Intention toward usual fruit and vegetable intake}

Fruit and vegetable intention is an individual's motivation or decision to consume usual fruit and vegetable intake. Fruit and vegetable intention is determined by the individual's attitude and perceived behavioral control. Fruit and vegetable intention will be measured by asking participants to rate, on a Likert-type scale, three statements: "I expect to eat at least fourand-a-half servings of fruits and vegetables per day," "I want to eat at least four-and-a-half servings of fruits and vegetables per day," and "I intend to eat at least four-and-a-half servings of fruits and vegetables per day."

\section{Other explanatory variables}

\section{Age}

The continuous variable age was measured as a numerical value with a true zero point. The question assessing age was "What is your current age in years?" Respondents entered numerical value corresponding to their current age in years.

\section{Sex}

The categorical variable sex was measured by two levels. Measurement levels were male or female. The question assessing sex was "What is your gender?" 


\section{Marital Status}

The categorical variable marital status was measured by two levels. The question assessing marital status was “Are you married?" Measurement levels were yes and no.

\section{Educational Level}

The categorical variable educational level was measured by three levels. The question assessing educational level was "What is your highest educational level?" Measurement levels were grade school, high school/GED/TASC, and college/technical.

\section{Family Income}

The numerical variable income was measured as categorical data by three measurement levels. The question assessing income was "What is your total annual household income?" Measurement levels were less than $\$ 20,000, \$ 20,000-\$ 40,000$, and higher than $\$ 40,000$.

\section{Statistical Analyses}

To analyze the unadjusted associations of: a) fruit and vegetable attitude and fruit and vegetable perceived behavioral control to fruit and vegetable intention; b) fruit and vegetable attitude to usual fruit and vegetable intake; c) fruit and vegetable perceived behavior control to usual fruit and vegetable intake among rural West Virginia residents of Mineral and Hampshire counties with pre-diabetes were tested with t-tests. To test the independent associations of fruit and vegetable attitude, fruit and vegetable perceived behavioral control, fruit and vegetable intention and usual fruit and vegetable intake a multiple linear regression was conducted. Multicollinearity, outliers, normality, linearity, and homoscedasticity were assessed. Residual scatterplots were generated and checked for normality, linearity, and homoscedasticity. Collinearity statistics were checked to ensure that tolerance was $>.10$ and variance inflation factors (VIF) were $<10$. We identified four outlying values on usual fruit and vegetable intake 
that distorted the associations. Therefore, these four values were removed from the adjusted analysis.

\section{Results}

\section{Description of the Sample by Demographic Characteristics}

Table 3 displays the comprehensive data of the subjects' demographic characteristics and risk factors for diabetes (Body mass index, waist circumference, and age). The sample comprised mainly white $(94.6 \%)$, middle-aged $(M=48.8, S D=17.5$ years $)$ women $(63.5 \%)$. Middle aged is considered aged 45 to 65 according to Oxford English Dictionary (2019). The CDC considers the ages of 45 to 64 at increased risk for the development of pre-diabetes (CDC, n.d.). More than half of participants had a college or technical school background (56.8\%), reported an annual household income of higher than $\$ 40,000$ (55.4\%), and were married (55.4\%).

\section{Description of the Sample by risk factors for Diabetes}

Majority of participants were at high risk for preventable diseases such as diabetes and cardiovascular disease based on their waist circumference. A majority of men (59\%) men had a waist circumference of 40 inches or greater and $62 \%$ women had a waist circumference of 35 inches or greater.

\section{Attitude toward Fruit and Vegetable Intake by demographic characteristics}

The average score for attitude toward fruit and vegetable intake was slightly higher among college educated as compared to those without college education (5.93 versus 5.43). The difference was statistically significant $(p=0.04)$. Although average score of attitude was highest (5.74) among those with family income over $\$ 40,000$, the differences in average score by income level were not statistically significant. (Table 3). 


\section{Perceived behavioral control toward Fruit and Vegetable by demographic characteristics}

Average scores of perceived behavioral control toward usual fruit and vegetable intake did not vary across demographic groups (Table 4). No differences were observed by age, sex, education, and marital status.

\section{Intention to take Fruit and Vegetable Intake by demographic characteristics}

Average scores for fruit and vegetable intention was higher among married participants as compared to not married (72.769 versus 59.581). This difference was statistically significant $(p=0.01)$. Statistically significant differences were not observed by age, sex, education, and income.

\section{Association of Demographic Characteristics to Fruit and Vegetable intake}

Table 3 presents the means and standard deviations of usual fruit and Vegetable intake by demographic characteristics. The table left panel include all 74 subjects and the right panel excluded 4 participants with influential observations. Overall, the average score for usual fruit and vegetable intake was 76.59 and SD 57.24 (Table 5). When 4 outliers were removed from the study sample, the average score was reduced to 66.93 and SD 40.57. Compared to participants with college/technical education, participants with less than college education had lower average scores in usual fruit and vegetable intake (51.581 versus $79.128, p=0.004)$. No other variables had statistically significant association to usual fruit and vegetable intake.

\section{Regression Analyses}

Simple ordinary Least Squares regressions were used to assess the unadjusted associations of each of the key independent variables to usual fruit and vegetable intake. These associations are graphically represented in Figures 3, 4, and 5. 


\section{Unadjusted Association of Attitude to Usual Fruit and Vegetable Intake}

Figure 3 displays the association of attitude to usual fruit and vegetable intake; the association was not statistically significant. Figure 3 also includes the simple linear regression equation $(\mathrm{Y}=4.9868 \mathrm{x}+38.344)$. The independent variables (fruit and vegetable attitude and education) in this model explain $11.8 \%(\mathrm{R}$ square $=0.118)$ of variation in usual fruit and vegetable intake $(\mathrm{F}$-value $=4.49, p=0.015)$.

\section{Unadjusted Association of Perceived Behavioral Control to Usual fruit and vegetable intake}

A statistically significant association of perceived behavioral control to usual fruit and vegetable intake was observed (Figure 4). Participants with higher perceived behavioral control had higher intake of fruits and vegetables (Beta $=4.99, p=0.009)$. For every one unit change in the independent variables (mean perceived behavioral control), there is a 4.99 change in usual fruit and vegetable intake. In this model the independent variables (fruit and vegetable perceived behavioral control and education) explain $15.9 \%(\mathrm{R}$ square $=0.159)$ of the variation in usual fruit and vegetable intake $(\mathrm{F}=6.34, p=0.003)$.

\section{Unadjusted Association of Intention to Usual Fruit and Vegetable intake}

Fruit and vegetable intention was positively associated to usual fruit and vegetable intake (Figure 5). Participants with higher scores in fruit and vegetable intention had higher intake of fruits and vegetables $($ Beta $=8.14, p=0.01)$. For every one unit change in the independent variables (mean intention), there is an 8.14 change in usual fruit and vegetable intake. Though model only explains $18.2 \%(\mathrm{R}$ Square $=0.182)$ of variation of usual fruit and vegetable intake, the independent variables (fruit and vegetable intention and education) explain usual fruit and vegetable intake $(\mathrm{F}$ value $=7.48, p=0.001)$. 


\section{Adjusted Associations of Attitude, Perceived Behavioral Control and Intention to Usual fruit and vegetable intake: Multiple Linear Regressions}

Independent associations of attitude, perceived behavioral control and intention to usual fruit and vegetable intake were assessed with multiple linear regression. Residual scatterplots were generated and checked for normality, linearity, and homoscedasticity. In the P-P plot of the regression standardized residual, the points laid in a reasonably straight diagonal line from bottom left to top right, suggesting no major deviations from normality. In the scatterplot of the standard residuals, the residuals were roughly rectangularly distributed with most scores concentrated in the center. The presence of outliers was checked by examining the Manalanobis distances produced by the multiple regression. Manalanobis distances of .13289 to 11.93694 in this regression model, did not exceed the critical value of 16.27 indicating no cases needed removal from this analysis.

\section{Tolerance and VIF}

Tolerance is an indicator of how much of the variability of the specified independent variable is not explained by the other independent variables on the model. Multicollinearity was assessed by examining the coefficients collinearity tolerance as well as pearson correlation coefficients for continuous variables. Multicollinearity was also ruled out by the variance inflation factor (VIF) values of the coefficients. VIF values above 10 would indicate multicollinearity. All three independent variables had VIF values lower than 10 (fruit and vegetable intake attitude $=1.165$; fruit and vegetable intake perceived behavioral control $=$ 1.440; fruit and vegetable intention $=1.315)$. However, Pearson correlation co-efficient estimates indicated that intention and perceived behavioral control were highly correlated 
(correlation $=0.45)$ and statistically significant $(\mathrm{p}<0.001)$. Therefore, separate regressions adjusted either perceived behavioral control or intention to usual fruit and vegetable intake.

\section{Multiple Linear Regression}

To assess the independent associations of attitude, perceived behavioral control, and intention to usual fruit and vegetable intake, after adjusting for education multiple linear regressions were performed.

\section{Multiple Linear Regression of Usual Fruit and Vegetable Intake: Adjusted for education}

As educational level was associated with usual fruit and vegetable intake, education was also included as one of the independent variables in separate multiple linear regressions. The results of these models are summarized in Table 6. All the models were significant in terms of F-values. The models with attitude, perceived behavioral control, and intention explained $11.8 \%$, $15.9 \%$, and $18.2 \%$ of the proportion of variance in fruit and vegetable intake respectively. In these models, even after adjusting for education, one unit increase in fruit and vegetable attitude was associated with 2.2 units in usual fruit and vegetable intake. Participants with college education had higher usual fruit and vegetable intake as compared to those without college education by 13.9 fruit and vegetable units. After adjusting for education, one unit increase in fruit and vegetable perceived behavioral control was associated with 7.2 units in fruit and vegetable intake. Participants with college education had higher fruit and vegetable intake as compared to those without college education by 24.9 fruit and vegetable intake units. After adjusting for education, one unit increase in fruit and vegetable intention was associated with 7.0 units in usual fruit and vegetable intake. Participants with college education had higher fruit and vegetable intake as compared to those without college education by 30.718 fruit and vegetable intake units. 
To assess the independent associations of fruit and vegetable attitude, fruit and vegetable perceived behavioral control to usual fruit and vegetable intake, a multiple regression was used. In this regression the following independent variables were included: mean attitude, mean perceived behavioral control, and education. Results of this regression are summarized in Table 7. This model explained $15.9 \%$ of the proportion of variance in usual fruit and vegetable intake. After adjusting for education and attitude, one unit increase in perceived behavioral control was associated with 7.4 units in fruit and vegetable intake, however, the association was marginally significant $(p=0.067)$. Participants with college education had higher fruit and vegetable intake as compared to those without college education by 22.7 fruit and vegetable intake units. There was no statistically significant association of fruit and vegetable attitude to usual fruit and vegetable intake.

To assess the independent associations of fruit and vegetable attitude and fruit and vegetable intention to usual fruit and vegetable intake, a multiple regression was used (Table 8). In this regression the following independent variables were included: mean attitude, intention, and education. Results of this regression are summarized in Table 8. This model explained $18.2 \%$ of the proportion of variance in usual fruit and vegetable intake. After adjusting for education and attitude, one unit increase in intention was associated with 7.0 units in fruit and vegetable intake $(p=0.026)$. Participants with college education had higher usual fruit and vegetable intake as compared to those without college education by 31.0 fruit and vegetable intake units. There was no statistically significant association of fruit and vegetable attitude to usual fruit and vegetable intake. 


\section{Chapter 5: Summary and Discussion}

This chapter includes a description of pre-diabetes in West Virginia residents, recaps the purpose of the study, theoretical framework that guided the research, comparison of study and findings to prior research. Discussion of the findings, implications for practice, future research and limitations of the study are also included.

\section{Pre-diabetes in West Virginia Residents}

Studies show that adults consuming recommended levels of fruit and vegetables were less likely to develop diabetes. West Virginian adults are faced with specific circumstances such as poverty, rurality and accessibility to fresh fruits. People living in rural areas who have prediabetes have unique challenges in making lifestyle changes needed to reduce the risk for progression of pre-diabetes into diabetes. This population often has challenges such poor selfmanagement, transportation issues, availability funding and resources for prevention or treatment of pre-diabetes (Health Resources and Services Administration of the U.S. Department of Health and Human Services, 2019). The participants in this study were from rural areas and possessed many of these challenges. Many of the participants had never been screened for pre-diabetes to their knowledge and were unaware of prevention programs available for pre-diabetes in their communities. Diabetes prevention programs promote healthy eating but do not offer additional information on the benefits of consuming fruits and vegetables toward the prevention of diabetes. And no studies are focusing on identifying factors which contribute to increasing intake of fruits and vegetables in rural adults with pre-diabetes.

\section{Theoretical Framework}

The study filled a significant knowledge gap in this area because there have been no studies that have applied the theory of planned behavior to a rural adult population with pre- 
diabetes. The theory of planned behavior was used as theoretical basis for this study. This theory postulates that achievement of a desired behavior depends on attitude, behavioral control, and intention. In the context of this study, fruit and vegetable intake represented desired behavior. Attitude refers to the degree to which an individual has a favorable or unfavorable view of consuming fruits and vegetables. Perceived behavioral control refer to the individual's perception of the difficulty or ease of performing fruit and vegetable intake. Greater perceived behavioral control can lead to higher fruit and vegetable intake. Behavioral intention refers to the motivational factors that influence fruit and vegetable intake intention. The stronger the fruit and vegetable intention, more fruits and vegetables will be consumed.

\section{Summary of Findings: Fruit and Vegetable Intake among West Virginia Residents}

The purpose of this study was to examine the associations of fruit and vegetable attitude, fruit and vegetable perceived behavior control, fruit and vegetable intention, and usual fruit and vegetable intake among rural West Virginia residents of Mineral and Hampshire counties with pre-diabetes. Analysis of survey demographics, select theory of planned behavior variables and fruit and vegetable intake in a group of West Virginian residents with prediabetes yielded several results. The results of the study showed that fruit and vegetable perceived behavioral control $(p$ $=0.009)$ and fruit and vegetable intention $(p=0.01)$ were significantly associated with usual fruit and vegetable intake in West Virginia residents with pre-diabetes. Fruit and vegetable attitude was not associated with usual fruit and vegetable intake in this study.

\section{Comparison of Study Findings to Prior Studies on Fruit and Vegetable Intake}

Aim 1: Examine associations of attitude, perceived behavioral control and intention of fruit and vegetable intake to usual fruit and vegetable intake in Mineral and Hampshire county residents in rural West Virginia with pre-diabetes. 
Contrary to the hypothesis, fruit and vegetable attitude was not associated with usual fruit and vegetable intake among this population. For example, in the study the correlation between fruit and vegetable attitude and fruit and vegetable intention was very weak $(0.22$ and not statistically significant), suggesting that the participant's attitude toward fruit and vegetable intake was not sufficient to influence their intention to consume fruit and vegetables and subsequently their fruit and vegetable intake behavior. One study by Kothe and Mullan (2014) reported attitude and perceived behavioral control predicted intention of fruit and vegetable intake at one week but not at one month. In this study, fruit and vegetable intake was assessed at one month, the only data collection point. Findings may differ if a one-week data collection is added for future research since food recall may be more precise or easier to recall more accurately if assessed in more recent timeframe.

Another possible reason for the finding of a limited role of attitude to explain fruit and vegetable intake may be the study population: rural West Virginian residents with pre-diabetes. The population characteristics/demographics differ significantly from those of other groups studied using the theory of planned behavior. Most studies of fruit and vegetable intake were conducted using the theory of planned behavior are in individuals with college education or healthy population.

The study also found a strong association between intention and perceived behavioral control, consistent with prior studies. DeBiasse et al. found that perceived behavioral control was the only significant predictor of fruit and vegetable intention (2017). This is consistent with the findings of this study in which perceived behavioral control and intention were the theory of planned behavior variables associated with fruit and vegetable intake behavior. 
In alignment with the hypothesis, fruit and vegetable perceived behavioral control $(p=$ $0.009)$ and fruit and vegetable intention $(p=0.01)$ were positively associated with usual fruit and vegetable intake among this population. This is consistent with previous literature. Evans et al. (2015) found the theory of planned behavior predictor variables were significantly correlated with fruit and vegetable intake in the college health population, however they found that behavioral resolve explained fruit and vegetable intake more than intention. This was the opposite in the population where fruit and vegetable perceived behavioral control accounted for less variation in usual fruit and vegetable intake than fruit and vegetable intention.

Aim 2: Determine the amount of variance contributed by each variable in the associations with usual fruit and vegetable intake among rural West Virginia residents in Mineral and Hampshire counties with pre-diabetes.

When examining the unadjusted associations with separate simple ordinary least squares regression, attitude explained only $1 \%$ of the variations in usual fruit and vegetable intake (Rsquare $=0.015)$ and the association was not statistically significant $(\mathrm{F}=1.05, p=0.3101)$. When the association of fruit and vegetable perceived behavioral control was examined, perceived behavioral control explained $9.5 \%(\mathrm{R}$-square $=0.095944)$ of the variation in usual fruit and vegetable intake. Similarly, fruit and vegetable intention explained 9.1\% (R-square = 0.091722) of the variance in fruit and vegetable intake.

A study by DeBiasse, Bowen, Pagoto, Massaro, Istfan and Quintiliani (2017) examined the role of theory of planned behavior variables to help explain fruit and vegetable intake among racial and ethnic women with low socioeconomic status. While perceived behavioral control was significantly associated with fruit and vegetable intake, DeBiasse et al., (2017) found that perceived behavioral control along with BMI accounted only for $8 \%$ of the variability in fruit 
and vegetable intake. This is also consistent with the findings in the study in which the model explained only $9 \%$ of the variation in fruit and vegetable intake in adults with pre-diabetes. However, the amount of variance contributed by intention is lower than those reported by prior studies. Kothe and Mullan (2014) conducted a secondary data analysis to explore the application of the theory of planned behavior to the prediction of fruit and vegetable intake. Kothe and Mullan (2014) found that theory of planned behavior accounted for $43 \%$ of the intention to consume fruits and vegetables. Another study by Menozzi, Sogari and Mora (2015) found that theory of planned behavior variables (perceived behavioral control and intention) accounted for $68 \%$ of fruit and vegetable intake in young adults. This is inconsistent with the study in which variables in the theory of planned behavior accounted only $9 \%$ of the variation in fruit and vegetable intake.

The differences in study findings may be explained by differences in study population, rurality, and access issues. Both Kothe and Mullan and Menozzi et al. studied college population and in the study, the theory of planned behavior was used to study fruit and vegetable intake in rural adults with pre-diabetes. One possible factor may be the accessibility differences of fresh fruits and vegetables in rural areas versus the location of college campuses most likely being in a more urban location. Another consideration should include factors that make it more difficult for older adults to consume fruit and vegetables. Nicklett and Kadell (2013) found barriers for accessing, preparing and eating fruits and vegetables in older adults which are often made worse by comorbidities, transportation and socioeconomic issues.

When performing separate multiple linear regressions with the theory of planned behavior variables and education, perceived behavioral control and fruit and vegetable intention were associated with usual fruit and vegetable intake. In this study's population, an increase in 
fruit and vegetable perceived behavioral control (one-unit change), equated to 4.99 units increase in usual fruit and vegetable intake and an increase in fruit and vegetable intention (one-unit change) equated to 8.14 units increase in usual fruit and vegetable intake. Intention is thought to be a direct antecedent to fruit and vegetable intake behavior. For participants in this study, fruit and vegetable intake may be driven by the participant's perception of their ability to perform the given behavior factoring into the participant's increased intention to consume fruit and vegetables.

When adding education as an independent variable in multiple linear regression the model explains $18 \%$ of the variation in usual fruit and vegetable intake in the study population, suggesting that education can influence fruit and vegetable intake. This is consistent with Hamki (2018), who found lower education levels to be a statistically significant variable associated with low fruit intake in rural adults. In the study, average score for fruit and vegetable attitude was lower in those with less than college education $(p=0.04)$. These results suggest that education should be considered as contributors to the variation in fruit and vegetable intake in future research.

\section{Implications for Practice}

Findings from this study revealed the associations of theory of planned behavior variables in West Virginian adults with pre-diabetes. Both fruit and vegetable perceived behavioral control and fruit and vegetable intention were identified as theory of planned behavior variables associated with an increase in usual fruit and vegetable intake. This information can be used to guide clinicians to focus fruit and vegetable interventions on efforts that will increase the participant's perception of self-efficacy and controllability and therefore fruit and vegetable intention to consume fruits and vegetables. Since fruit and vegetable intention was the identified 
as the main theory of planned behavior predictor variable impacting fruit and vegetable intake, Diabetes Prevention programs may use this information to promote health behaviors that will increase participants confidence, self-efficacy and motivation to consume fruit and vegetables. Qamar, McIntosh and Hicks (2017) found improved perceived behavioral control toward fruit and vegetable intake in participants after attending an online educational program focusing on nutrition, included an increase fruits and vegetable consumption. Improvement in perceived behavioral control toward fruit and vegetable intake may impact fruit and vegetable intake intention and fruit and vegetable intake behavior, thus assist in the prevention of diabetes.

Even though attitude toward fruit and vegetable intake was not associated with fruit and vegetable intake in the population, it has been associated with increased intention to consume fruit and vegetables in previous studies and avenues to increase participant's attitude toward fruit and vegetable intake should be considered. Given the unique barriers that may affect a rural adult with pre-diabetes' intake of fruits and vegetables, availability, accessibility and socioeconomic status should be considered. Aggarwal, Monsivais, Cook and Drewnowski (2014) found that shoppers who had a positive attitude toward healthy eating made healthy food choices regardless of the cost level of the supermarket, independent of their socioeconomic status. Primary care providers, nurses, dieticians, diabetes prevention programs can use interventions aimed to increase fruit and vegetable intake by using interventions that are designed to increase participant's attitude toward fruit and vegetable consumption. Izumi, Eckhardt, Wilson, and Cahill (2016) conducted a cooking intervention within an existing home visiting program to help increase attitude toward fruit and vegetable intake in adults with pre-K students. This study found a significant increase in participant's confidence as well, which may lead to increased intention to consume fruits and vegetables. Implementation of a similar intervention into diabetes 
prevention programs may help to alleviate some of the barriers associated with fruit and vegetable intake in rural adults with pre-diabetes.

\section{Future Research}

In this study the theory of planned behavior variables accounted for only $9 \%$ of the variation in usual fruit and vegetable intake and adding the education variable increased the account for usual fruit and vegetable intake variation to $18.2 \%$. Future studies in this population should include modifiable characteristics and other variables that can explain a very large variance of the fruit and vegetable intake in rural adult patients with prediabetes.

In this sample, the average score for fruit and vegetable attitude was highest in participant's whose annual household income was greater than $\$ 40,000$. A study by Leone, Beth, Ickes, Macguire, Nelson, Smith, Tate and Ammerman (2012), found that cost was a barrier that affected participant's attitude toward fruits and vegetable and rural participants were more likely to report cost as a barrier than urban participants. In this study, cost was reported to be more of a barrier than accessibility. This aspect was not evaluated by the study; however, it is a consideration that may be a contributing factor to the low contribution for variation in fruit and vegetable intake in this population and should be evaluated in future research.

A descriptive study with a larger sample size from rural adults with pre-diabetes and a corresponding urban cohort would allow for comparisons to be made. If the samples are found to be similar in terms predictor variables for fruit and vegetable intake, the same interventions aimed at increasing the main predictor variable(s) could be used in these populations.

A longitudinal study on factors affecting fruit and vegetable intake in rural West Virginian residents with pre-diabetes would allow for a more in-depth understanding of how fruit and vegetable intake varies over time. This type of study should include groups and subgroups 
of fruit and vegetables and additional evaluation of cost for fruit and vegetables, as well as demographic variables including socioeconomical status, income level and education level since these variables have been identified as being barriers to fruit and vegetable intake in rural adults.

Special attention to timing of growing season and availability of fresh produce should also be taken into consideration since this may affect the frequency and amount of fruit and vegetables consumed. A comparative-effectiveness study, could assess the effectiveness of adding an intervention that is based on increasing knowledge of fruit and vegetable health benefits, protective nature of consuming fruits and vegetables, and serving size amounts. Another factor to consider is portion size of fruits and vegetables. Bensley, Van Eenwyk and Bruemmer (2003) stress the importance of including portion size in questionnaires assessing fruit and vegetable intake since it can increase the prevalence of fruit and vegetable intake reported.

\section{Limitations}

This study had several limitations. The feasibility descriptive study was based on a convenience sample collected during January 2019. The data collection time of assessing the participant's intake of fruits and vegetables was in January. This may have impacted the amount of fruit and vegetables consumed by individuals in this geographic location since the intake of fruits and vegetables may have been significantly lower due to the limited availability of fresh produce. West Virginia's growing season typically runs from July through mid-October. Another limitation is that the sample size limited the ability to include more variables in the model. We could include only one of two of the theory of planned behavioral variables and education. Another limitation of this study is that participants may have adjusted their reporting of fruit and vegetable intake because they know they were being observed. The final limitation was the relatively small sample size. A larger sample size would have enabled us to include more 
variables such as cost barriers, "fruit-vegetable desert" areas, and others that may influence fruit and vegetable take. It must be noted that despite a small sample size, a strong association of theory of planned behavior variables and education, suggesting that future studies may be able to target these variables to improve fruit and vegetable intake and thus reduce the onset of diabetes.

\section{Conclusions}

Among residents with pre-diabetes in rural West Virginia setting of this study, the higher perceived behavioral control and intention toward fruit and vegetable intake were associated with higher fruit and vegetable intake. Fruits and vegetables play an important role in the prevention of diabetes as well as many other chronic conditions. With West Virginia's high prevalence of pre-diabetes and diabetes, interventions aimed at increasing fruit and vegetable intake in rural residents with pre-diabetes is an important component in changing the culture of health in West Virginia and stopping the progression of pre-diabetes to diabetes.

Nurses and nurse clinicians can play an important role in assisting West Virginia residents with pre-diabetes reduce their risk for the development of diabetes by providing interventions aimed increasing fruit and vegetable intake. Nurses can provide education on ways to increase fruit and vegetable intake, offer interventions to increase consumption including cooking classes, identify resources for fresh produce for patients, refer to diabetes prevention programs, lobby for change in policy on having fruits and vegetables at work place parties, function and health fairs, and by screening for daily fruit and vegetable intake and offering encouragement to consume the recommended daily amount of fruits and vegetables. 


\section{References}

Aggarwal, A., Monsivais, P., Cook, A., \& Drewnowski, A. (2014). Positive attitude toward healthy eating predicts higher diet quality at all cost levels of supermarkets. Journal of the Academy of Nutrition and Dietetics, 114(2), 266-272. doi:10.1016/j.jand.2013.06.006

Ajzen, I. (1991). The theory of planned behavior. Organizational Behavior and Human Decision Processes, 50(2), 179-179.

Ajzen, I. (2005). Attitudes, personality and behavior (2nd ed.). Maidenhead, UK: Open

Ajzen, I. (2011). The theory of planned behavior: Reactions and reflections. Psychology \& Health, 26(9), 1113-1127. doi:10.1080/08870446.2011.613995

American Diabetes Association. (2018). Statistics About Diabetes. Retrieved March 25, 2018, from http://www, diabetes.org/diabetes-basics/statistics/

American Diabetes Association. (n.d.) The Burden of Diabetes in West Virginia. Retrieved on May 13, 2018 from http://main.diabetes.org/dorg/PDFs/Advocacy/burden-ofdiabetes/west-virginia.pdf

Aparecida Monteiro, L., de Cássia Lopes Chaves, É., Salgado Souza, V. H., Nogueira, D. A., da Graça Pereira, M., \& Hollanda Iunes, D. (2015). Questionnaire of planned behavior in diabetes - foot care: validation. Online Brazilian Journal of Nursing, 14(3), 255-262.

Bai, Y. K., \& Dinour, L. M. (2017). Validation of a theory of planned behavior-based questionnaire to examine factors associated with milk expression. Journal of Human Lactation, 33(4), 658-665. doi:10.1177/0890334417695205

Bensley, L., Van Eenwyk, J., Bruemmer BA. Measuring fruit and vegetable consumption: providing serving size information doubles estimated percent eating five per day. Journal of American Dietetic Associations, 1996, 96:1040-1042. 
Center for Disease Control and Prevention. (2015). Assessing Your Weight | Healthy Weight | CDC. Retrieved March 2018, from https://www.cdc.gov/healthyweight/assessing/index.html

Center for Disease Control and Prevention. (n.d.). Could You Have Prediabetes? Retrieved 2017, from https://www.cdc.gov/prediabetes/takethetest/

Centers for Disease Control and Prevention. (2011). Behavioral Risk Factor Surveillance System Survey Questionnaire. Retrieved from https://www.cdc.gov/brfss/questionnaires/index.htm

Centers for Disease Control and Prevention. (2015a). How to use fruits and vegetables to help manage your weight. Retrieved from https://www.cdc.gov/healthyweight/healthy_eating/fruits_vegetables.html

Centers for Disease Control and Prevention. (2015b). Improving your eating habits. Retrieved from https://www.cdc.gov/healthyweight/losing_weight/eating_habits.html

Centers for Disease Control and Prevention. (2015c). Morbidity and Mortality Weekly Report. Retrieved from https://search.cdc.gov/search?subset=MMWR\&query=fruits\%2Band\%2Bvegetable\&utf8 $=\% \mathrm{E} 2 \% 9 \mathrm{C} \% 93 \&$ affiliate $=$ cdc-main\&sitelimit $=$ www.cdc.gov $\% 2 \mathrm{Fmmwr} \% 2 \mathrm{~F}$

Centers for Disease Control and Prevention. (2016). National diabetes prevention program. Retrieved from http://www.cdc.gov/diabetes/prevention/prediabetes-type2/index.html Centers for Disease Control and Prevention. (2017). Diabetes Home. Retrieved from https://www.cdc.gov/diabetes/basics/prediabetes.htm

Centers for Disease Control and Prevention. (2018). National Diabetes Prevention Program. Retrieved from https://www.cdc.gov/diabetes/prevention/index.html 
Centers for Disease Control and Prevention. (n.d.). Surveillance of Fruit and Vegetable Intake Using the Behavioral Risk Factor Surveillance System [Pdf].

Condrasky, M., Baruth, M., Wilcox, S., \& Carter, C. (2013). Predictors of change in fruit and vegetable consumption in a faith-based intervention with African American adults. Family \& Community Health, 36(3), 236-47. doi:10.1097/FCH.0b013e318293159b

Cooper, A., Sharp, S. Lentjes, M., Luben, R., Khaw, K., Wareham, N., \& Forough, N. (2015). The association between a biomarker score for fruit and vegetable intake and incident type 2 diabetes: The ePIC-Norfolk study. European Journal of Clinical Nutrition, 69(4), 449-54. doi:10.1038/ejcn.2014.246

Dall, T., Yang W., Halder P., Pang, B., Massoudi, M., Wintfeld., N., Semilla, A., Franz, J., and Hogan, P. (2014) The economic burden of elevated blood glucose levels in 2012: Diagnosed and undiagnosed diabetes, gestational diabetes mellitus, and prediabetes. Diabetes Care, 37, 3172-3179

Dean, W., \& Sharkey, J., Program for Research in Nutrition and Health Disparities, Department of Social and Behavioral Health, School of Rural Public Health, Texas A\&M Health Science Center, College Station, TX. (2011). Rural and urban differences in the associations between characteristics of the community food environment and fruit and vegetable intake. Journal of Nutrition Education and Behavior, 43(6), 426-433. doi:10.1016/j.jneb.2010.07.001

DeBiasse MA, Bowen DJ, Pagoto SL, Massaro JM, Istfan N and Quintiliani LM. The Role of Attitude, Control and Intention to Explain Fruit and Vegetable Intake among Racial/Ethnic Minority Women with Low Socioeconomic Status. Int J Nutr Sci. 2017; 2(1): 1015 . 
Diabetes Prevention Research Group. (2002). Reduction in the incidence of type 2 diabetes with lifestyle intervention or metformin. Acp Journal Club, 137, 55-55.

Division of Health Promotion and Chronic Disease. (2018). Welcome to HPCD. Retrieved from https://dhhr.wv.gov/hpcd/Pages/default.aspx

Emanuel, A., McCully, S., Gallagher, K., \& Updegraff, J. (2012). Theory of planned behavior explains gender difference in fruit and vegetable consumption. Appetite, 59(3), 693-697. doi:10.1016/j.appet.2012.08.007

Evans, R., Kawabata, M., \& Thomas, S. (2015). Prediction of fruit and vegetable intake: The importance of contextualizing motivation. British Journal of Health Psychology, 20(3), 534-548. doi:10.1111/bjhp.12123

Francis, J., Eccles, M. P., Johnston, M., Walker, A. E., Grimshaw, J. M., Foy, R., ... Bonetti, D. ((2004). Constructing questionnaires based on the theory of planned behaviour: A manual for health services researchers. Newcastle upon Tyne, UK: Centre for Health Services Research, University of Newcastle upon Tyne.

Godinho, C. A., Alvarez, M., Lima, M. L., \& Schwarzer, R. (2014). Will is not enough: coping planning and action control as mediators in the prediction of fruit and vegetable intake. British Journal of Health Psychology, 19(4), 856-870. doi:10.1111/bjhp.12084

Hamki, Kadija, "Examining Rural and Urban Differences in Fruit and Vegetable Intake Among Obese and Overweight Adults in Georgia (BRFSS 2015).” Thesis, Georgia State University, 2018. https://scholarworks.gsu.edu/iph_theses/626

Health Resources and Services Administration of the U.S. Department of Health and Human Services. (2019). Challenges - Rural Diabetes Prevention Toolkit. Retrieved from https://www.ruralhealthinfo.org/toolkits/diabetes/4/challenges 
Huang, E., Brown, E., Ewigman, B., Foley, E., \& Meltzer, D. (2007). Patient perceptions of quality of life with diabetes-related complications and treatments. Diabetes Care, 30(10), 2478-2483. doi:10.2337/dc07-0499

IBM. (2017). IBM SPSS Statistics for Windows, Version 25.0.[Computer Software]. Armonk, NY: IBM Corp.

Kamphuis, C.B., Giskes, K., de Bruijn, G.J., Wendel-Vos, W., Brug, J., \& van Lenthe, F.J. (2006). Environmental determinants of fruit and vegetable consumption among adults: a systematic review. British Journal of Nutrition, 96(4):620-35

Kanaya, A., Santoyo-Olsson, J., Gregorich, S., Grossman, M., Moore, T., \& Stewart, A. (2012). The live well, be well study: A community-based, translational lifestyle program to lower diabetes risk factors in ethnic minority and lower-Socioeconomic status adults. American Journal of Public Health, 102(8), 1551-1558

Kieffer, E., Welmerink, D., Sinco, B., Welch, K., Rees Clayton, E., Schumann, C., \& Uhley, V. (2014). Dietary outcomes in a Spanish-language randomized controlled diabetes prevention trial with pregnant Latinas. American Journal of Public Health, 104(3), 526533. doi:10.2105/AJPH.2012.301122

Kothe, E. J., \& Mullan, B. A. (2015). Interaction effects in the theory of planned behaviour: Predicting fruit and vegetable consumption in three prospective cohorts. British Journal of Health Psychology, 20(3), 549-562. doi:10.1111/bjhp.12115

Kurotani, K., Nanri, A., Goto, A., Mizoue T., Noda, M., Kato, M., Inoue, M., Tsugane, S., Japan Public Health Center-based Prospective Study Group. (2013). Vegetable and fruit intake and risk of type 2 diabetes: Japan public health center-based prospective study. The British Journal of Nutrition, 109(4), 709-17. doi:10.1017/S0007114512001705 
Ledoux, T., Hingle, M., \& Baranowski, T. (2011). Relationship of fruit and vegetable intake with adiposity: A systematic review. Obesity Reviews, 12(5), 150. doi:10.1111/j.1467789X.2010.00786.x

Lien, N., Lytle, L., \& Komro, K. (2016). Applying theory of planned behavior to fruit and vegetable consumption of young adolescents. American Journal of Health Promotion, 16(4), 189-197. doi:10.4278/0890-1171-16.4.189

Lucia A. Leone, Diane Beth, Scott B. Ickes, Kathleen MacGuire, Erica Nelson, Robert Andrew Smith, Deborah F. Tate \& Alice S. Ammerman (2012) Attitudes Toward Fruit and Vegetable Consumption and Farmers' Market Usage Among Low-Income North Carolinians, Journal of Hunger \& Environmental Nutrition, 7:1, 64-76, DOI: 10.1080/19320248.2012.651386

Luke, A. \& Cooper, R. (2013). Physical activity does not influence obesity risk: Time to clarify the public health message. International Journal of Epidemiology, 42(6), 1831-6. doi:10.1093/ije/dyt159

Menezes, M., Costa B., Oliveira, C., \& Lopes, A. (2017). Local food environment and fruit and vegetable consumption: An ecological study. Preventive Medicine Reports, 5(C), 13-20. doi:10.1016/j.pmedr.2016.10.015

Menozzi, D., Sogari, G., \& Mora, C. (2015). Explaining vegetable consumption among young adults: An application of the theory of planned behaviour. Nutrients, 7(9), 7633-7650. doi:10.3390/nu7095357

Middaugh, A., MS, Fisk, P., MS, Brunt, A., PhD, RD, \& Rhee, Y., PhD, RD. (2012). Few associations between income and fruit and vegetable consumption. Journal of Nutrition Education and Behavior, 44(3), 196-203. doi:10.1016/j.jneb.2011.10.003

National Association of Chronic Disease Directors. (n.d.). West Virginia: Roadmap for the National DPP Lifestyle Change Program (Rep.). Leavitt Partners. 
National Center for Chronic Disease Prevention and Health Promotion. (n.d.). CDC Prediabetes Screening Test[pdf]. Retrieved from https://www.cdc.gov/diabetes/prevention/pdf/prediabetestest.pdf

National Center for Chronic Disease Prevention and Health Promotion. (2013). State Indicator Report. Retrieved from www.cdc.gov/nutrition/downloads/state-indicator

National Center for Health Statistics. (2017). Retrieved from https://www.cdc.gov/nchs/products/databriefs/db292.htm

Nelson D., Holtzman D., Bolen J., Stanwyck C., Mack K. (2001). Reliability and validity of measures from the Behavioral Risk Factor Surveillance System (BRFSS). Sozial-und Praventivmedizin, 46, S3-S42

Nelson D., Holtzman D., Bolen J., Stanwyck C., Mack K. (2001). Reliability and validity of measures from the Behavioral Risk Factor Surveillance System (BRFSS). Sozial-und Praventivmedizin, 46, S3-S42

Nicklett, E. J., \& Kadell, A. R. (2013). Fruit and vegetable intake among older adults: a scoping review. Maturitas, 75(4), 305-312. doi:10.1016/j.maturitas.2013.05.005

Oxford English Dictionary. (2018). Fruit | Definition of fruit in English by Oxford Dictionaries. Retrieved from https://en.oxforddictionaries.com/definition/fruit

Oxford English Dictionary. (2018). Vegetable | Definition of vegetable in English by Oxford Dictionaries. Retrieved from https://en.oxforddictionaries.com/definition/vegetable Pearson Education, Inc.

Pontzer, H., Durazo-Arvizu, R., Dugas, L., Plange-Rhule, J., Bovet, P., Forrester, T., Lambert, E., Cooper, R., Schoeller, D., \& Luke, A. (2016). Constrained total energy expenditure 
and metabolic adaptation to physical activity in adult humans. Current Biology, 26(3), 410-7. doi:10.1016/j.cub.2015.12.046

Qamar, Z., McIntosh, A., \& Hicks, K. (2017). Improved perceived behavioral control in choosing fruits and vegetables as a result of the online nutrition program for south asians. Journal of the Academy of Nutrition and Dietetics, 117(9), 58.

doi:10.1016/j.jand.2017.06.173

Retrieved from https://dhhr.wv.gov/hpcd/data_reports/Documents/Big\%20Picture\%20WV\%20Diabetes \%20Infographic.pdf

Rolls, B.J., Ello-Martin J.A., \& Tohill, B.C. (2004) What can intervention studies tell us about the relationship between fruit and vegetable consumption and weight management? Nutrition Reviews, 62, 1-17.

Safabakhsh, M., Koohdani, F., Bagheri, F., Siassi, F., Khajehnasiri, F., \& Sotoudeh, G. (2017). Fruit and vegetable intake and pre-diabetes: A case-control study. European Journal of Nutrition, 6(6). doi:10.1007/s00394-017-1569-x

Smith-Warner, S.A., Elmer, P.J., Fosdick, L., Tharp, T.M., \& Randall, B. (1997). Reliability and comparability of three dietary assessment methods for estimating fruit and vegetable intakes. Epidemiology, 8(2), 196-201

Storey, M., \& Anderson, P. (2014). Income and race/ethnicity influence dietary fiber intake and vegetable consumption. Nutrition Research, 34(10), 844-850.

doi:10.1016/j.nutres.2014.08.016

Tabachnick, B. G., \& Fidell, L. S. (2007). Using multivariate statistics (5th ed.). Boston, MA: 
The State of Obesity. (2018). Obesity Rates \& Trends. Retrieved June 17, 2018, from https://stateofobesity.org/rates/

The World Health Organization. (2018). Increasing fruit and vegetable consumption to reduce the risk of noncommunicable diseases. Retrieved from http://www.who.int/elena/titles/fruit_vegetables_ncds/en/

Tomasone, J., Meikle, N., \& Bray, S. (2015). Intentions and trait self-control predict fruit and vegetable consumption during the transition to first-year university. Journal of American College Health, 63(3), 172-9. doi:10.1080/07448481.2014.1003375

Trust for America's Health and Robert Wood Johnson Foundation. (2018). States with the Highest Type 2 Diabetes Rates. Retrieved from https://www.stateofobesity.org/lists/highest-rates-diabetes/

University of Pittsburgh. (2018). Pre-diabetes. Retrieved from http://www.diabetesprevention.pitt.edu/index.php/for-the-public/diabetes-and-relatedconditions/pre-diabetes/ University Press.

West Virginia Department of Health and Human Resources. (2012). West Virginia Behavioral Risk Factor Surveillance System Report (pp. 1-165, Rep.). Charleston, WV: Bureau for Public Health. doi:http://www.wvdhhr.org/bph/hsc/pubs/brfss/2012/BRFSS2012.pdf West Virginia Department of Human Resources and Bureau for Public Health. (n.d.).

Willett, W., \& Lenart, E. (1998). Reproducibility and validity of food frequency questionnaires. In W. Willett (Ed.), Nutritional epidemiology (pp. 101-147). New York: Oxford University Press. 


\section{Tables}

Table 1

Fruit and Vegetable Intake Study Protocol

\begin{tabular}{|c|c|c|c|}
\hline $\begin{array}{c}\text { Step } \\
\text { Number }\end{array}$ & Step & $\begin{array}{l}\text { Measures/Data } \\
\text { Collected }\end{array}$ & Responsibility \\
\hline 1 & $\begin{array}{l}\text { Investigator (I) or Certified Diabetes Educator } \\
\text { (CDE) attend community gatherings, fairs, } \\
\text { events, churches, malls/shopping centers }\end{array}$ & None & I, CDE \\
\hline 2 & $\begin{array}{l}\text { I or CDE gives potential participant flyer about } \\
\text { the study and answers questions. }\end{array}$ & None & $\mathrm{I}, \mathrm{CDE}$ \\
\hline 3 & $\begin{array}{l}\text { I or CDE reviews inclusion/ exclusion criteria to } \\
\text { ensure participant's eligibility and explains } \\
\text { consent form with potential participant. }\end{array}$ & $\begin{array}{c}\text { Consent } \\
\text { (explained) }\end{array}$ & $\mathrm{I}, \mathrm{CDE}$ \\
\hline 4 & $\begin{array}{l}\text { If participant agrees, I/CDE obtains informed } \\
\text { consent \& assigns participant a code for } \\
\text { deidentification (ID) purposes. Participant is } \\
\text { provided this number to be used throughout } \\
\text { study in place of his/her name. }\end{array}$ & $\begin{array}{l}\text { Consent } \\
\text { (verbal) }\end{array}$ & I, CDE \\
\hline 5 & $\begin{array}{l}\text { Participant begins study: } \\
\text { a. I/CDE pulls top envelope. } \\
\text { b. Participant completes all surveys inside } \\
\text { envelope. } \\
\text { c. I/CDE explains there is no follow up. } \\
\text { d. I/CDE gives participant compensation for } \\
\text { participation. }\end{array}$ & $\begin{array}{l}\text { Demographic, } \\
\text { TPB, FVI }\end{array}$ & $\mathrm{I}, \mathrm{CDE}$ \\
\hline 6 & $\begin{array}{l}\text { CDE contacts I to report Participant's ID number } \\
\text { and records all of the above data onto calendar/ } \\
\text { log. }\end{array}$ & $\begin{array}{l}\text { Demo data, } \\
\text { TPB data, FVI } \\
\text { data, record of } \\
\text { compensation }\end{array}$ & $\mathrm{CDE}$ \\
\hline 7 & $\begin{array}{l}\text { Upon study completion, I meets with statistician } \\
\text { committee member to enter data into SPSS and } \\
\text { discuss findings. }\end{array}$ & None & $\begin{array}{l}\text { I, statistician } \\
\text { committee } \\
\text { member }\end{array}$ \\
\hline
\end{tabular}




\section{Table 2}

Variables in the Association of Attitude, Perceived Behavioral Control, and Intention with Fruit and Vegetable Intake among Rural West Virginian Residents of Mineral and Hampshire counties with Pre-diabetes Study

\begin{tabular}{|c|c|c|}
\hline Variable & $\begin{array}{l}\text { Definition and } \\
\text { Operationalization }\end{array}$ & Measurement/Instrument \\
\hline $\begin{array}{l}\text { Fruit \& Vegetable } \\
\text { Attitude }\end{array}$ & $\begin{array}{l}\text { Person's evaluation or appraisal of } \\
\text { fruit and vegetable intake; favorable } \\
\text { (positive) or unfavorable (negative) }\end{array}$ & $\begin{array}{l}\text { Attitude Direct Measure } \\
\text { Questions (1-7; higher mean } \\
\text { indicates more positive fruit } \\
\text { and vegetable intake attitude) }\end{array}$ \\
\hline $\begin{array}{l}\text { Fruit \& Vegetable } \\
\text { Perceived Behavioral } \\
\text { Control }\end{array}$ & $\begin{array}{l}\text { Perception that person has/does not } \\
\text { have capacity to consume fruit and } \\
\text { vegetable; includes self-efficacy } \\
\text { and perceived controllability to } \\
\text { consume fruit and vegetables }\end{array}$ & $\begin{array}{l}\text { Perceived Behavioral Control } \\
\text { Direct Measure Questions (1- } \\
7 \text {; higher mean indicates } \\
\text { higher fruit and vegetable } \\
\text { intake control perception) }\end{array}$ \\
\hline $\begin{array}{l}\text { Fruit \& Vegetable } \\
\text { Intention }\end{array}$ & $\begin{array}{l}\text { Indication of how hard person is } \\
\text { willing to try or how much effort } \\
\text { person is planning to exert to } \\
\text { perform fruit and vegetable intake } \\
\text { behavior; person's motivation to act }\end{array}$ & $\begin{array}{l}\text { Intention Direct Measure } \\
\text { Questions (1-7; higher mean } \\
\text { indicates more positive fruit } \\
\text { and vegetable intake } \\
\text { intention) }\end{array}$ \\
\hline $\begin{array}{l}\text { Background Factors } \\
\text { (Demographics) }\end{array}$ & $\begin{array}{l}\text { Age (years) } \\
\text { Weight (pounds) and height } \\
\text { (inches); } \\
\text { BMI (m2; calculated from weight } \\
\text { and height) } \\
\text { Waist Circumference (inches) } \\
\text { Gender (male or female) } \\
\text { Married (no or yes } \\
\text { Predominant ethnicity (White or } \\
\text { other) } \\
\text { Highest educational level (Less than } \\
\text { high school or high school and } \\
\text { beyond) } \\
\text { Socioeconomic status (income) } \\
\text { Resident of West Virginia (yes or } \\
\text { no) }\end{array}$ & Demographic Survey \\
\hline $\begin{array}{l}\text { Usual Fruit and } \\
\text { Vegetable Intake }\end{array}$ & $\begin{array}{l}\text { Persons evaluation of their usual } \\
\text { frequency of fruit and vegetable } \\
\text { intake over the previous month. }\end{array}$ & $\begin{array}{l}\text { Behavioral Risk Factor } \\
\text { Surveillance Survey (BRFSS) } \\
\text { Fruit and Vegetable Module }\end{array}$ \\
\hline
\end{tabular}


Table 3

\section{Table 3}

Description of Demographic Characteristics of the Sample Adults (age $\geq 18$ years) with Pre-Diabetes in West Virginia

$$
\operatorname{ALL}(\mathbf{N}=74)
$$

Sex

Female

Male

\section{Race}

White

Non-White

70

94.6

Education

Not college

32

42

43.3

College/Technical

$\begin{array}{rlr}32 & & 43.3 \\ 42 & & 56.7 \\ & & \\ & & 10.8 \\ 25 & & 33.8 \\ 41 & & 55.4 \\ \text { Mean } & \text { SD } & \\ 48.89 & 17.45 & \end{array}$

Age in years

$48.89 \quad 17.45$

Note: Based on a convenient sample of 74 adults, aged 18 years or older recruited at community events from Hampshire and Mineral counties. 
Table 4

Table 4

Description of Perceived Behavioral control, Attitude, and By Demographic Characteristics

Adults (age $\geq 18$ years) with Pre-Diabetes in West Virginia $(N=74)$

\begin{tabular}{|c|c|c|c|c|c|c|}
\hline & \multicolumn{2}{|l|}{ Attitude } & \multicolumn{2}{|l|}{ PBC } & \multicolumn{2}{|c|}{ Intention } \\
\hline & Mean & SD & Mean & SD & Mean & SD \\
\hline ALL & 5.71 & 1.03 & 5.08 & 1.24 & 4.90 & 1.53 \\
\hline \multicolumn{7}{|l|}{ Sex } \\
\hline Female & 5.565 & 1.023 & 4.926 & 1.186 & 4.642 & 1.456 \\
\hline Male & 5.798 & 1.038 & 5.181 & 1.283 & 5.050 & 1.573 \\
\hline \multicolumn{7}{|l|}{ Marital Status } \\
\hline Not Married & 5.500 & 1.084 & 4.788 & 1.233 & 4.4241 & 1.530 \\
\hline Married & 5.884 & 0.967 & 5.329 & 1.219 & 5.285 & 1.443 \\
\hline \multicolumn{7}{|l|}{ Education } \\
\hline Not college & 5.4301 & 1.093 & 4.617 & 1.493 & 4.667 & 1.529 \\
\hline College/Technical & 5.929 & 0.939 & 5.446 & 0.881 & 5.079 & 1.532 \\
\hline \multicolumn{7}{|l|}{ Income } \\
\hline Less than $\$ 20,000$ & 5.656 & 1.232 & 4.344 & 1.451 & 4.792 & 1.181 \\
\hline$\$ 20,000-\$ 40,000$ & 5.690 & 0.969 & 5.190 & 1.049 & 4.440 & 1.696 \\
\hline Greater than & & & & & & \\
\hline$\$ 40,000$ & 5.738 & 1.055 & 5.171 & 1.297 & 5.203 & 1.447 \\
\hline
\end{tabular}

Age in years $\dagger$

Pearson correlation

coefficient

0.04

0.04

$-0.08$

Note: Based on a convenient sample of 74 adults, aged 18 years or older recruited at community events from Hampshire and Mineral counties.

$\dagger$ Association between perceived behavioral control and age in years was assessed with Pearson correlation coefficient.

PBC: Perceived Behavioral Control 
Table 5

\begin{tabular}{|c|c|c|c|c|}
\hline \multicolumn{5}{|c|}{$\begin{array}{c}\text { Table } 5 \\
\text { Description of Usual Fruit and Vegetable Intake } \\
\text { By Demographic Characteristics } \\
\text { Adults (age } \geq 18 \text { years) with Pre-Diabetes in West Virginia }\end{array}$} \\
\hline & \multicolumn{2}{|c|}{ ars) with Pre-Diabete } & \multicolumn{2}{|c|}{$\begin{array}{l}\text { Without Outliers }(\mathrm{N}= \\
\text { 70) }\end{array}$} \\
\hline & Mean & SD & Mean & SD \\
\hline ALL & 76.59 & 57.24 & 66.93 & 40.57 \\
\hline \multicolumn{5}{|l|}{ Sex } \\
\hline Female & 65.630 & 50.366 & 59.615 & 40.281 \\
\hline Male & 82.894 & 60.455 & 71.250 & 40.569 \\
\hline \multicolumn{5}{|l|}{ Marital Status } \\
\hline Not Married & 71.758 & 65.086 & 59.581 & 43.245 \\
\hline Married & 80.488 & 50.555 & 72.769 & 37.850 \\
\hline \multicolumn{5}{|l|}{ Education } \\
\hline Not college & 59.438 & 57.490 & 51.581 & 37.069 \\
\hline College/Technical & 89.667 & 54.129 & 79.128 & 39.476 \\
\hline \multicolumn{5}{|l|}{ Income } \\
\hline Less than $\$ 20,000$ & 35.625 & 35.629 & 35.625 & 35.629 \\
\hline $\begin{array}{l}\$ 20,000-\$ 40,000 \\
\text { Greater than }\end{array}$ & 65.760 & 35.255 & 65.760 & 35.255 \\
\hline$\$ 40,000$ & 91.195 & 66.213 & 74.486 & 42.441 \\
\hline
\end{tabular}

\section{Age in years $\dagger$ \\ Pearson correlation coefficient} $-0.04582$ $-0.01980$

Note: Based on a convenient sample of 74 adults, aged 18 years or older recruited at community events from Hampshire and Mineral counties.

$\dagger$ Association between age in years and usual fruit and vegetable intake was assessed with Pearson correlation coefficient. 
Table 6

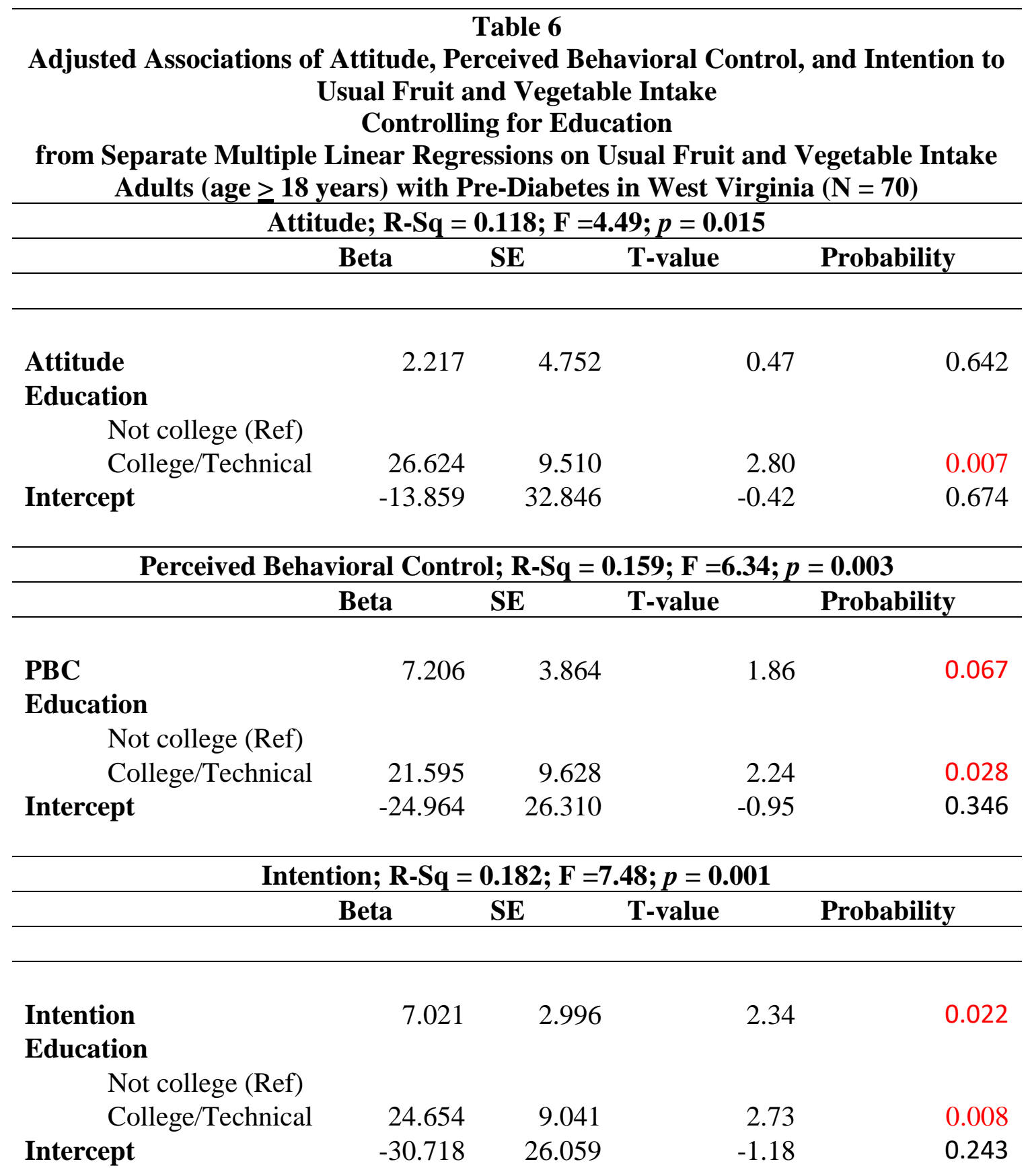

Note: Based on a convenient sample of 70 adults, aged 18 years or older recruited at community events from Hampshire and Mineral counties. Beta estimates are derived from separate multiple linear regressions on fruit and vegetable intake.

SE: Standard Error 
Table 7

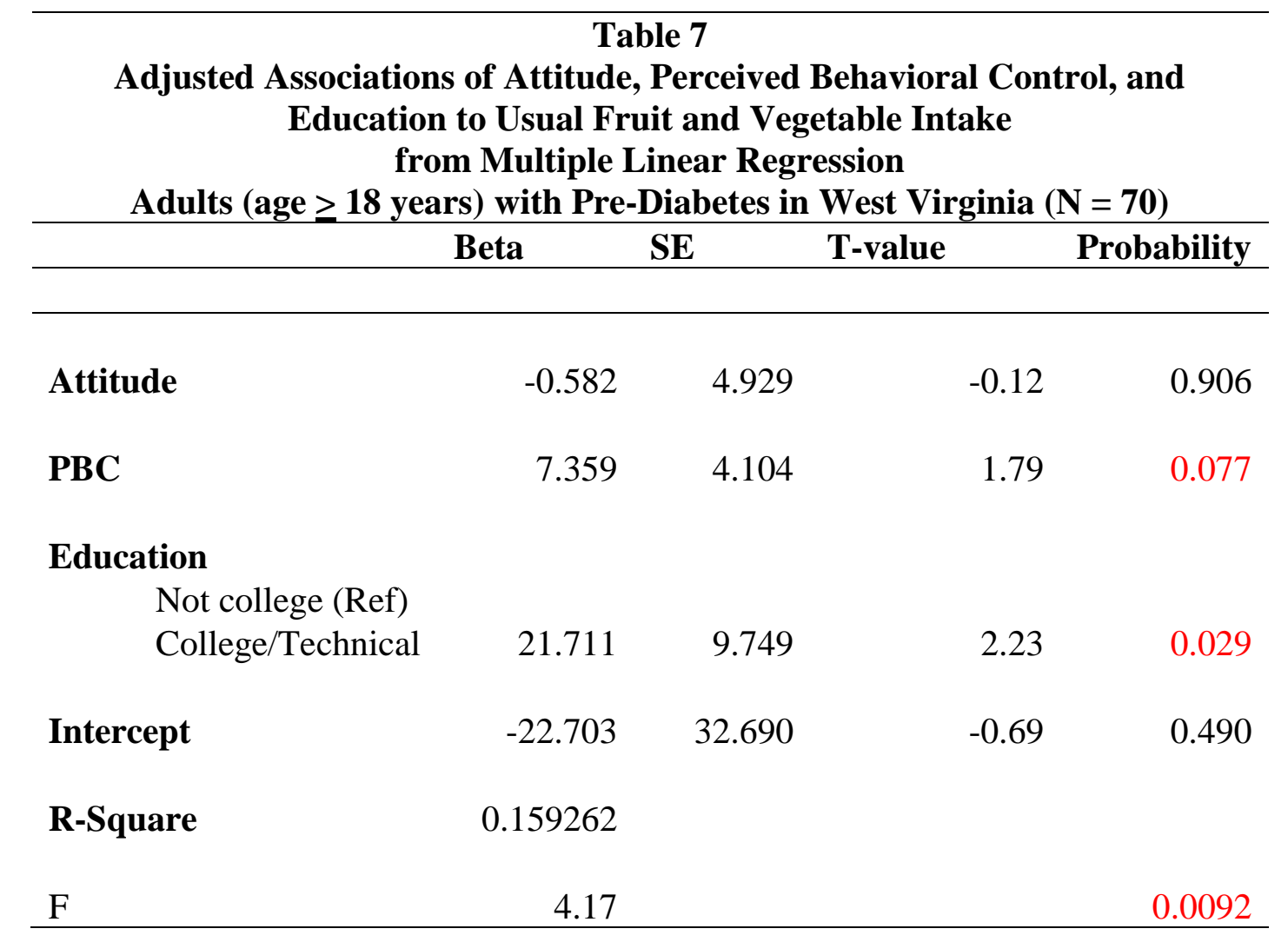

Note: Based on a convenient sample of 70 adults, aged 18 years or older recruited at community events from Hampshire and Mineral counties.

PBC: Perceived Behavioral Control

SE: Standard Error 
Table 8

\section{Table 8}

Adjusted Associations of Attitude, Intention and Education to Usual Fruit and Vegetable Intake from Multiple Linear Regression

Adults (age $\geq 18$ years) with Pre-Diabetes in West Virginia $(\mathrm{N}=70)$

Note:

Based on

\begin{tabular}{|c|c|c|c|c|}
\hline ras & Beta & SE & T-value & Probability \\
\hline Attitude & 0.077 & 4.705 & 0.02 & 0.987 \\
\hline Intention & 7.011 & 3.081 & 2.28 & 0.026 \\
\hline \multicolumn{5}{|l|}{ Education } \\
\hline \multicolumn{5}{|l|}{ Not college (Ref) } \\
\hline College/Technical & 24.626 & 9.268 & 2.66 & 0.010 \\
\hline Intercept & -31.037 & 32.749 & -0.95 & 0.347 \\
\hline R-Square & 0.182 & & & \\
\hline $\mathrm{F}$ & 4.91 & & & 0.0039 \\
\hline
\end{tabular}




\section{Figures}

\section{Figure 1}

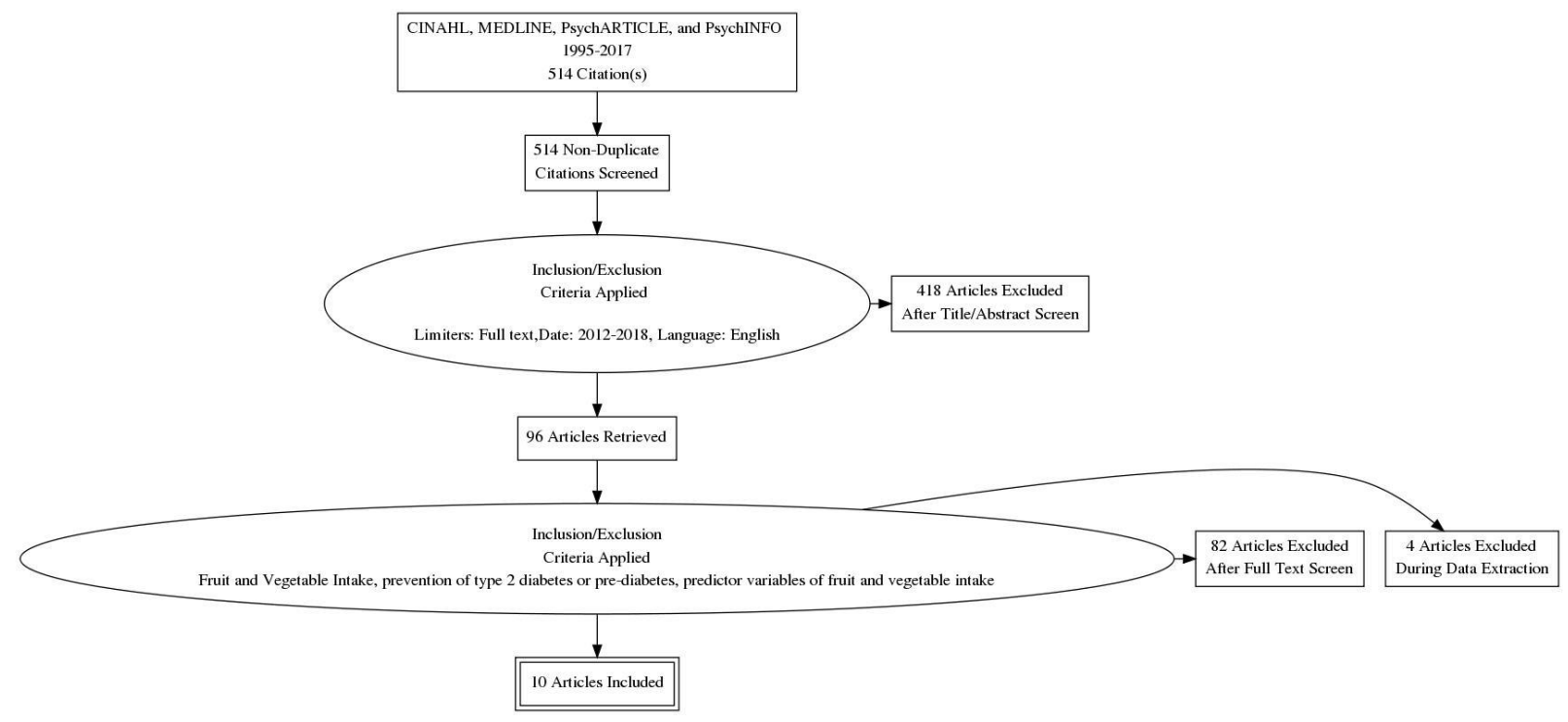

Figure 1. Literature search process 
Figure 2

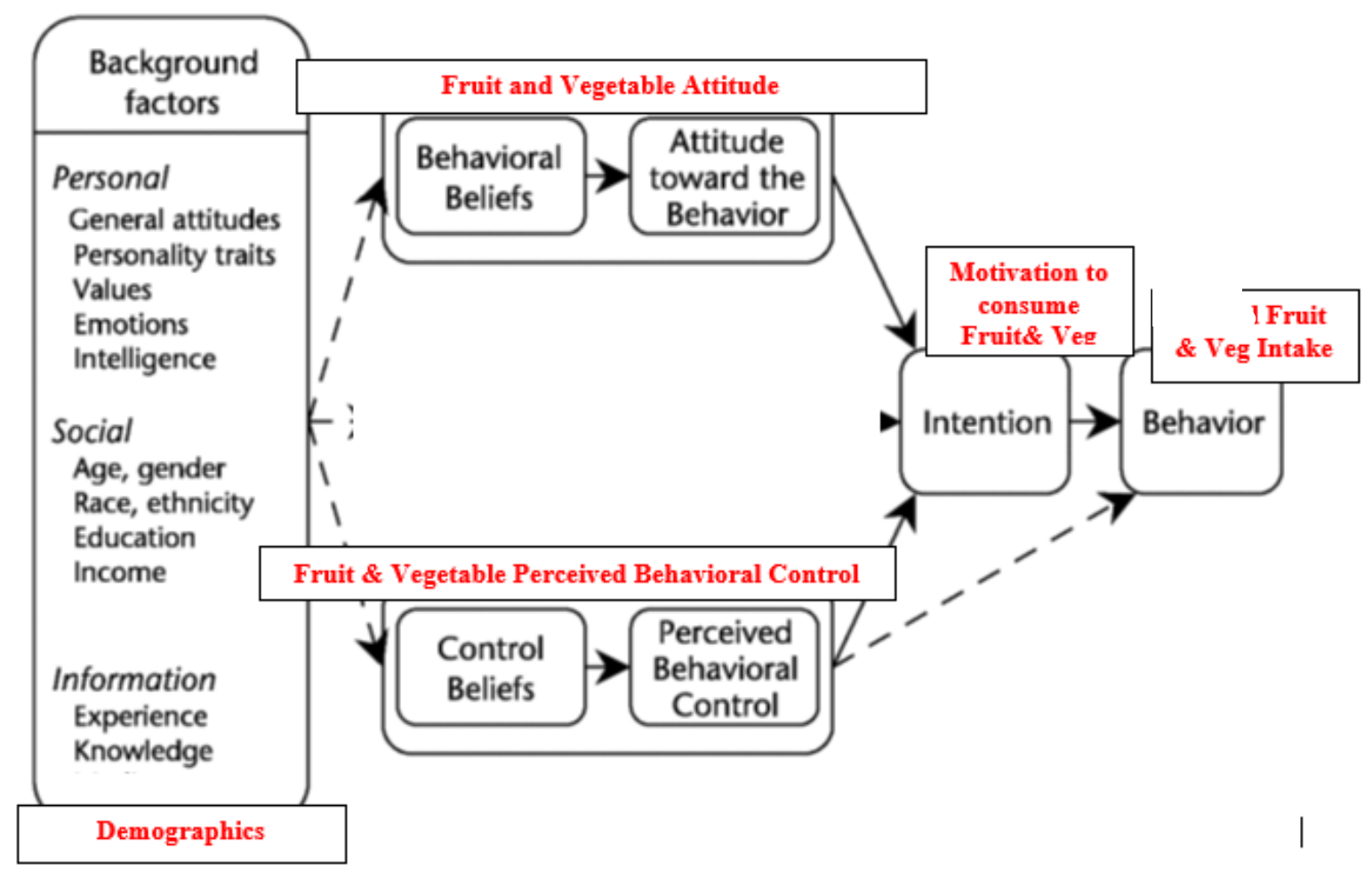

Figure 2. Associations of fruit and vegetable intake (in overlaid boxes with red text) to promote fruit and vegetable intake using the theory of planned behavior as the guiding framework.

Adapted from Attitudes, Personality and Behavior (2nd ed., p. 135), by I. Ajzen, 2005, Berkshire, England: Open University Press. 
Figure 3

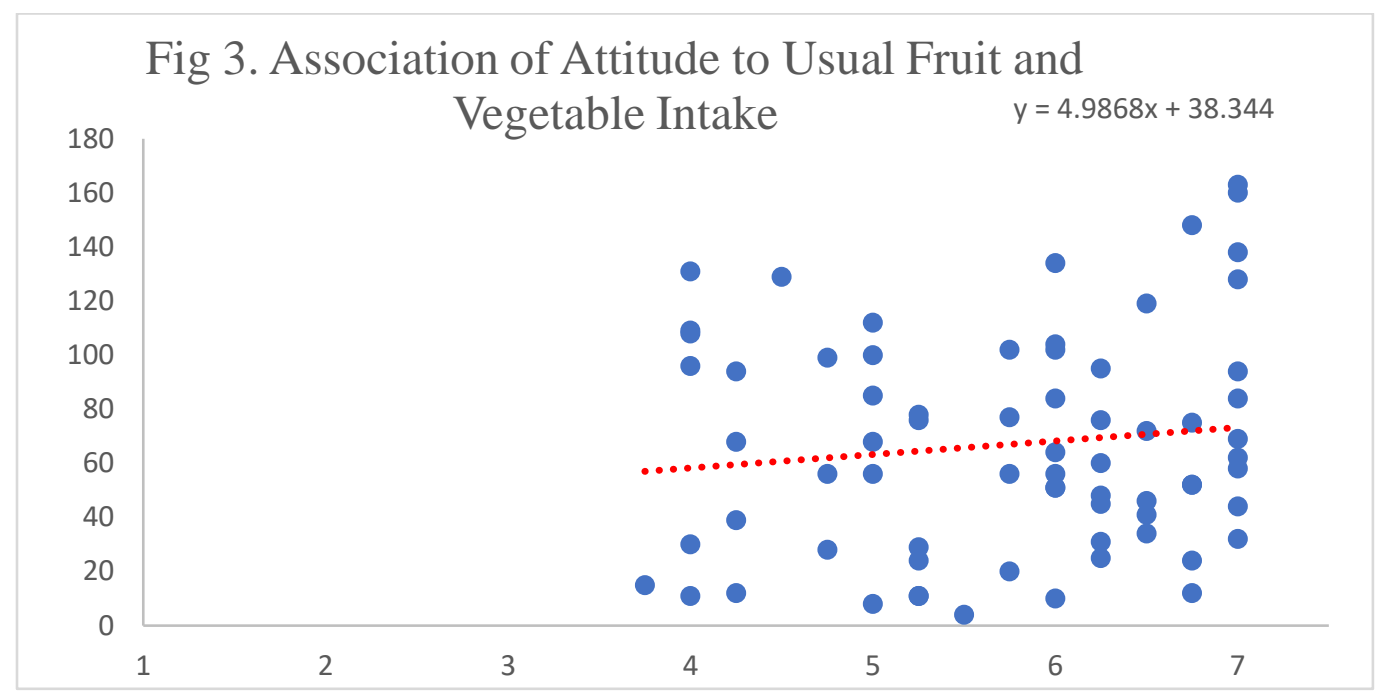

Figure 3. Associations of attitude to usual fruit and vegetable intake in West Virginian residents with pre-diabetes in Mineral and Hampshire counties. 


\section{Figure 4}

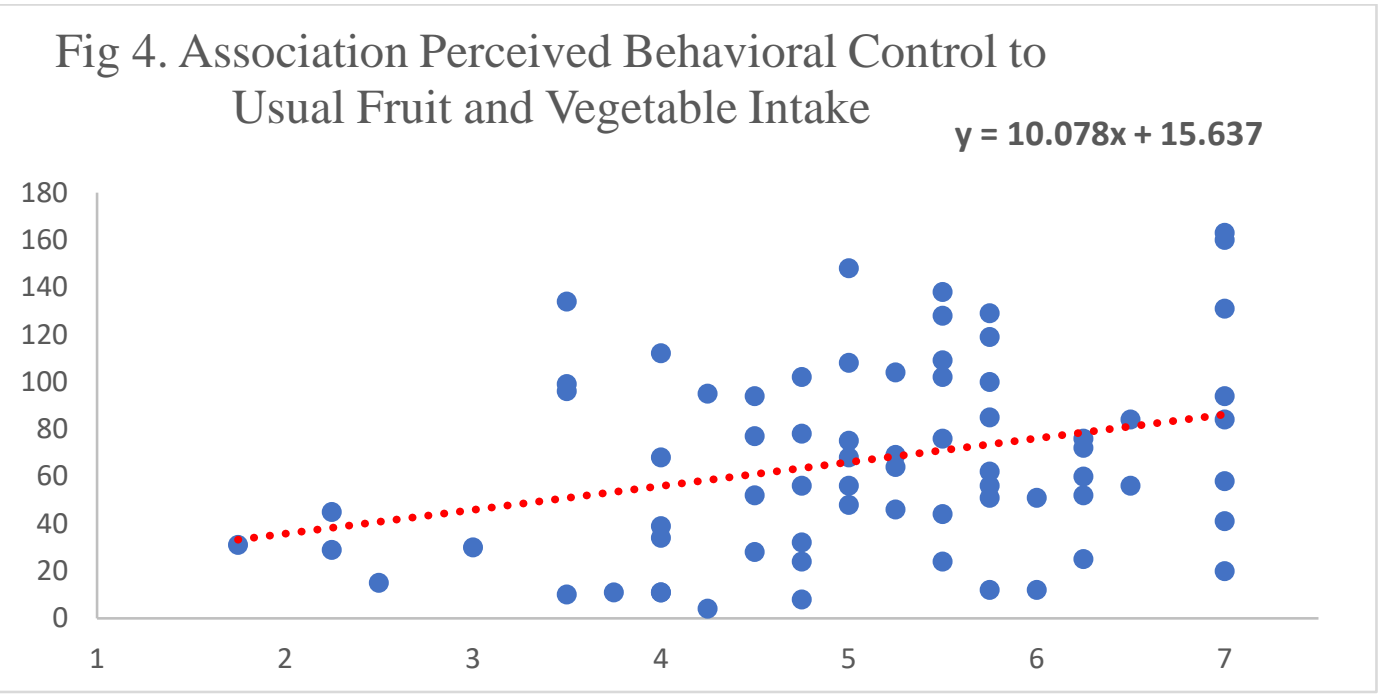

Figure 4. Associations of perceived behavioral control to usual fruit and vegetable intake in West Virginian residents with pre-diabetes in Mineral and Hampshire counties. 
Figure 5

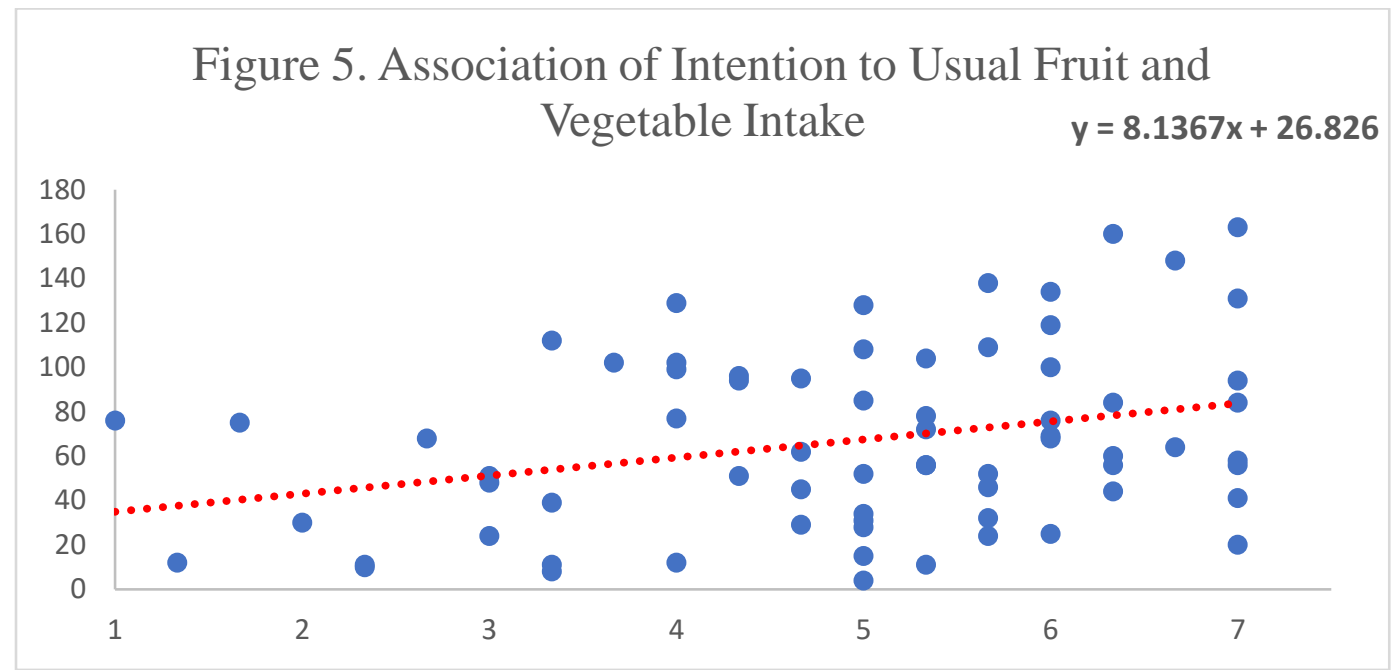

Figure 5. Associations of intention to usual fruit and vegetable intake in West Virginian residents with pre-diabetes in Mineral and Hampshire counties. 


\section{Appendices}

\section{Appendix A}

Participant Identification Number

Date

1. What is your current age in years?

2. What is your current weight in pounds?

3. What is your current height in feet/inches? $\mathrm{Ft}$ In

4. What is your gender? Please circle: Male Female

5. Are you married? Please circle: No Yes

6. What is your main ethnicity? Please circle: White Black Hispanic Other Race?

7. What is your highest education level? Please circle:

Grade School High School/GED/TASC College/Technical

8. What is your total annual household income? Please circle:

Less than $\$ 20,000 \$ 20,000$ to $\$ 40,000$ Higher than $\$ 40,000$

9. Are you a currently a West Virginia resident? No Yes

10. County of residence

11. Waist circumference (inches) 
Participant Identification Number

Date

1. During the past month, how many times per day, week or month did you drink $100 \%$ PURE fruit juices? Do not include fruit-flavored drinks with added sugar or fruit juice you made at home and added sugar to. Only include $100 \%$ juice.

$$
\begin{aligned}
& \text { 1_ }- \text { Per day } \\
& 2 \text { - Per week } \\
& 3 \text { _ } \text { Per month }
\end{aligned}
$$

555 Never

777 Don't Know/ Not Sure

999 Refused

2. During the past month, not counting juice, how many times per day, week, or month did you eat fruit? Count fresh, frozen, or canned fruit.

$$
\begin{aligned}
& \text { 1_ }- \text { Per day } \\
& \text { 2_ }- \text { Per week } \\
& \text { 3_ } \text { Per month }
\end{aligned}
$$

555 Never

777 Don't Know/ Not Sure

999 Refused

3. During the past month, how many times per day, week, or month did you eat cooked or canned beans, such as refried, baked, black, garbanzo beans, beans in soup, soybeans, edamame, tofu, or lentils. Do NOT include long green beans.

$$
\begin{aligned}
& 1 \ldots \text { _ Per day } \\
& 2 \_ \text {Per week } \\
& 3 \_ \text {_ Per month } \\
& 555 \text { Never } \\
& 777 \text { Don't Know/ Not Sure } \\
& 999 \text { Refused }
\end{aligned}
$$

4. During the past month, how many times per day, week, or month did you eat dark green vegetables, for example broccoli or dark leafy greens including romaine, chard, collard greens, or spinach?
$1_{-}$- Per day
2_- Per week
$3 \ldots$ Per month
555 Never
777 Don't Know/ Not Sure
999 Refused 
Participant Identification Number

Date

5. During the past month, how many times per day, week, or month did you eat orange-colored vegetables, such as sweet potatoes, pumpkin, winter squash, or carrots?
$1_{-}$_ Per day
2_- Per week
3 _ Per month
555 Never
777 Don't Know/ Not Sure
999 Refused

6. Not counting what you just told me about, during the past month, about how many times per day, week, or month did you eat OTHER vegetables? Examples of other vegetables include tomatoes, tomato juice or V-8 juice, corn, eggplant, peas, lettuce, cabbage, and white potatoes that are not fried such as baked or mashed potatoes.

$1 \_$Per day

2_- Per week

$3 \ldots$ Per month

555 Never

777 Don't Know/ Not Sure

999 Refused 
Participant Identification Number Date

Each question in this section refers to measuring Fruit and Vegetable intake attitude.

1. For me, eating at least four-and-a-half servings of fruits and vegetables per day is

$\begin{array}{lcrrrrrrr}\text { Harmful } & 1 & 2 & 3 & 4 & 5 & 6 & 7 & \text { Beneficial } \\ & \text { extremely } & \text { quite } & \text { slightly } & \text { neither } & \text { slightly } & \text { quite extremely }\end{array}$

2. For me, eating at least four-and-a-half servings of fruits and vegetables per day is

$\begin{array}{ccccccccc}\text { Good } & 1 & 2 & 3 & 4 & 5 & 6 & 7 & \text { Bad }\end{array}$

3. For me, eating at least four-and-a-half servings of fruits and vegetables per day is

$\begin{array}{rrrrrrrrr}\text { Pleasant } & 1 & 2 & 3 & 4 & 5 & 6 & 7 & \text { Unpleasant } \\ & \text { extremely } & \text { quite } & \text { slightly } & \text { neither } & \text { slightly } & \text { quite } & \text { extremely }\end{array}$

4. For me, eating at least four-and-a-half servings of fruits and vegetables per day is

$\begin{array}{ccccccccc}\text { Worthless } & 1 & 2 & 3 & 4 & 5 & 6 & 7 & \text { Useful } \\ & \text { extremely } & \text { quite } & \text { slightly } & \text { neither } & \text { slightly } & \text { quite } & \text { extremely } & \end{array}$


Each question in this section refers to measuring Fruit and Vegetable intake perceived behavioral control.

5. I am confident that I could eat at least four-and-a-half servings of fruits and vegetables per day if I wanted to.

$\begin{array}{rrrrrrrrr}\text { Strongly disagree } & 1 & 2 & 3 & 4 & 5 & 6 & 7 & \text { Strongly agree } \\ \text { extremely } & \text { quite } & \text { slightly } & \text { neither } & \text { slightly } & \text { quite } & \text { extremely }\end{array}$

6. For me to eat at least four-and-a-half servings of fruits and vegetables per day is

$\begin{array}{ccccccccc}\text { Easy } & 1 & 2 & 3 & 4 & 5 & 6 & 7 & \text { Difficult } \\ & \text { extremely } & \text { quite } & \text { slightly } & \text { neither } & \text { slightly } & \text { quite extremely } & \end{array}$

7. The decision to eat at least four-and-a-half servings of fruits and vegetables per day is beyond my control.

$\begin{array}{rrrrrrrrr}\text { Strongly disagree } & 1 & 2 & 3 & 4 & 5 & 6 & 7 & \text { Strongly agree } \\ \text { extremely } & \text { quite } & \text { slightly } & \text { neither } & \text { slightly } & \text { quite extremely }\end{array}$

8. Whether I eat at least four-and-a-half servings of fruits and vegetables per day is entirely up to me.

$\begin{array}{rrrrrrrrr}\text { Strongly disagree } & 1 & 2 & 3 & 4 & 5 & 6 & 7 & \text { Strongly agree } \\ \text { extremely } & \text { quite } & \text { slightly } & \text { neither } & \text { slightly } & \text { quite extremely }\end{array}$


Each question in this section refers to measuring Fruit and Vegetable intake intention.

9. I expect to eat at least four-and-a-half servings of fruits and vegetables per day.

$\begin{array}{rrrrrrrrr}\text { Strongly disagree } & 1 & 2 & 3 & 4 & 5 & 6 & 7 & \text { Strongly agree } \\ & \text { extremely } & \text { quite } & \text { slightly } & \text { neither } & \text { slightly } & \text { quite } & \text { extremely }\end{array}$

10. I want to eat at least four-and-a-half servings of fruits and vegetables per day.

$\begin{array}{rrrrrrrrr}\text { Strongly disagree } & 1 & 2 & 3 & 4 & 5 & 6 & 7 & \text { Strongly agree } \\ & \text { extremely } & \text { quite } & \text { slightly } & \text { neither } & \text { slightly } & \text { quite } & \text { extremely }\end{array}$

11. I intend to eat at least four-and-a-half servings of fruits and vegetables per day.

$\begin{array}{rrrrrrrrr}\text { Strongly disagree } & 1 & 2 & 3 & 4 & 5 & 6 & 7 & \text { Strongly agree } \\ \text { extremely } & \text { quite } & \text { slightly } & \text { neither } & \text { slightly quite extremely }\end{array}$




\section{Appendix B}

1. Are any items ambiguous or difficult to answer?

2. Does the questionnaire feel too repetitive?

3. Does it feel too long?

4. Does it feel too superficial?

5. Are there any annoying features of the wording or formatting?

6. Are there inconsistent responses that might indicate that changes in response endpoints are problematic for respondents who complete the questionnaire quickly? 


\section{Appendix C}

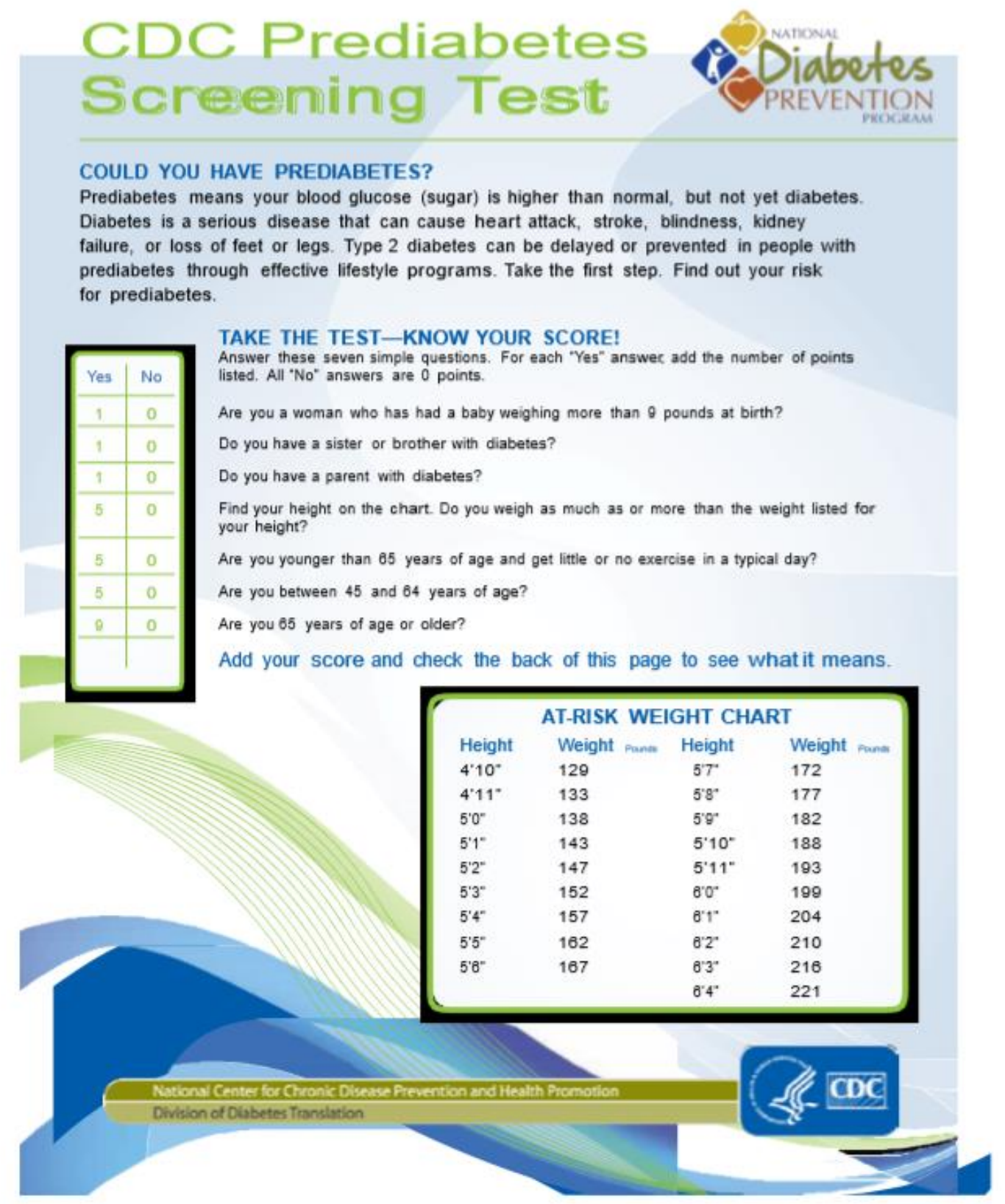


